\title{
Blame Crime on Name? People With Bad Names Are More Likely to Commit Crime
}

\author{
Han-Wu-Shuang Bao ${ }^{1,2}$, Jianxiong Wang ${ }^{3}$, Huajian Cai ${ }^{1,2^{*}}$ \\ ${ }^{1}$ Institute of Psychology, Chinese Academy of Sciences, Beijing 100101, China \\ ${ }^{2}$ Department of Psychology, University of Chinese Academy of Sciences, Beijing 100049, China \\ ${ }^{3}$ School of Economics, Beijing International Studies University, Beijing 100024, China \\ * Corresponding author: Huajian Cai \\ Institute of Psychology, Chinese Academy of Sciences \\ 16 Lincui Road, Chaoyang District, Beijing 100101, China \\ E-mail: caihj@psych.ac.cn
}

Word count: 7311

Introduction: 1221

Method: 2293

Results: 2697

Discussion: 1100 


\begin{abstract}
Past evidence has revealed the interpersonal and intrapersonal costs of bearing bad names.

The current research examined whether bad names predicted a more serious social outcome: criminal behavior. We found name-crime links based on a large dataset of 981,289 Chinese criminals (as compared to the whole Chinese population and a national representative sample of 1,000,000 non-criminal controls). People whose names were unpopular, negative, or implied lower warmth/morality were more likely to commit property and violent crime, whereas people whose names implied higher competence/assertiveness were more likely to commit violent and economic crime. Critically, lower warmth/morality of name still robustly predicted crime when controlling for demographic confounds and addressing alternative explanations. Furthermore, possessing a less warm/moral name predicted the motive for intentionally committing crime. These findings demonstrate the ethical costs of bearing bad/immoral names and enrich the understanding of how social-cognitive dimensions (warmth-competence) are associated with human behavior.
\end{abstract}

Keywords: name, crime, criminal behavior, social cognition, morality, big data 


\section{Blame Crime on Name? People With Bad Names Are More Likely to Commit Crime}

"As his name is, so is he; Nabal is his name, and folly is with him."

-Bible (1 Samuel 25:25)

Bad names may invite trouble. As the Bible says, people with a "bad" name may also possess a "bad" trait. Substantial evidence has revealed that bearing a bad (e.g., unpopular, undesirable) name predicted worse interpersonal outcomes (e.g., being unfavorably treated by others; Gebauer, Leary, \& Neberich, 2012) and worse intrapersonal outcomes (e.g., poorer mental health; Twenge \& Manis, 1998). Some preliminary evidence has even shown that juveniles with a less popular name have a higher tendency toward delinquent or problematic behavior (Kalist \& Lee, 2009). In the current research, we focus on a possible link between bad names and criminal behavior - a more serious social outcome that hazards both other people and the whole society. Specifically, we investigate name-crime links comprehensively across seven categories of crime and four dimensions of name. Examining the name-crime links will uncover the ethical costs of bearing bad names beyond its well-documented costs on interpersonal and intrapersonal outcomes.

\section{Criminal Behavior and Its Potential Link With Personal Names}

Criminal behavior, a form of antisocial behavior in which people violate the criminal law, is extremely harmful to both individuals and the society (Bartol \& Bartol, 2017). There are multiple factors together contributing to a higher risk of criminal or antisocial behavior:

(1) biological and genetic factors (e.g., malnutrition, neurotoxins, brain injury, low-activity 
monoamine-oxidase-A [MAOA] gene); (2) parental and familial factors (e.g., single-parent household, parental neglect, domestic violence); (3) personality and demographic factors (e.g., high impulsivity, high neuroticism, low agreeableness, low conscientiousness; being male, being young); and (4) social and economic factors (e.g., peer rejection, unemployment, poverty, low socioeconomic status [SES], economic inequality) (for overviews and books, see, e.g., Andrews \& Bonta, 2010; Bartol \& Bartol, 2017; Durrant, 2018; for reviews and meta-analyses, see, e.g., Assink et al., 2015; Besemer, Ahmad, Hinshaw, \& Farrington, 2017; Gard, Dotterer, \& Hyde, 2019; Jones, Miller, \& Lynam, 2011; Vize, Miller, \& Lynam, 2018). Is criminal behavior also related to personal names? Some preliminary evidence has suggested a link between name and crime. To date, the only research directly examining the name-crime link focused on name popularity and juvenile delinquency: based on a namelevel analysis, this research demonstrated that American adolescents with unpopular (i.e., uncommon) names were more likely to commit delinquent behavior (Kalist \& Lee, 2009). This preliminary finding lays the foundation for a more comprehensive examination of the name-crime links beyond merely name popularity and merely juvenile delinquency. Indeed, name popularity, as an objective feature of name indicating how frequently a name is used in the national population (Bao, 2020; Bao et al., 2020), may not be the only name feature that is associated with crime. Some other name features may have an even more direct link with crime. Moreover, juvenile delinquency is just an early manifestation of criminal tendency before adulthood. Therefore, it is necessary to test, by using larger datasets and more rigorous methods, whether any name-crime link exists in real life among various name dimensions and 
across different crime categories.

Besides the only direct evidence on the name-crime link regarding name popularity (Kalist \& Lee, 2009), some indirect evidence has shown that name valence (also known as "name desirability", "name positivity", and "name attractiveness") is negatively associated with a host of maladaptive interpersonal and intrapersonal outcomes, which suggests a possible link between name negativity and criminal behavior. Positivity vs. negativity is a classic and basic evaluative dimension in social psychology (Cacioppo \& Berntson, 1994). Prior findings shows that possessing a negative (undesirable) name not only has interpersonal costs (e.g., others' negative impression, interpersonal neglect, peer rejection; Busse \& Seraydarian, 1979; Erwin, 1993; Gebauer et al., 2012; Harari \& McDavid, 1973; McDavid \& Harari, 1966) but also has intrapersonal costs (e.g., lower self-esteem and well-being, poorer psychological adjustment and educational obtainment, worse academic achievement, and more problematic behavior such as smoking; Busse \& Seraydarian, 1978; Garwood, 1976; Gebauer et al., 2012; Twenge \& Manis, 1998). Therefore, it is reasonable to deduce that negative names may also be associated with other negative (even worse) life outcomes, especially the one that often comes after psychological maladjustment and educational failure: criminal behavior.

Beyond the objective feature (popularity) and subjective feature (valence) of name, recent literature further indicates that personal names have two other important features that tap into the two fundamental dimensions of content in social cognition: name warmth and name competence (Newman, Tan, Caldwell, Duff, \& Winer, 2018). In social perception, 
people first wonder if the intention of other individuals is good or bad-i.e., "warmth"; for the second priority, people wonder if the others are able to enact their intention-i.e., "competence" (Fiske, 2018; Fiske, Cuddy, \& Glick, 2007). With regard to names, people also have a perception of how warm or competent a person with a certain name is likely to be (Newman et al., 2018). Notably, warmth involves more nuanced facets—warmth and morality_that focus on "communal content" and refer to "getting along and forming bonds"; competence involves more nuanced facets - competence and assertiveness - that focus on "agentic content" and refer to "getting ahead and pursuing goals" (Abele \& Wojciszke, 2014, 2019). Furthermore, warmth and competence may have distinct effects on human behavior. For instance, substantial evidence has shown that the two personality facets "warmth" and "assertiveness" (both belong to the "Extraversion" factor of the Five-Factor Model) were negatively and positively correlated with antisocial behavior, respectively (Jones et al., 2011; Vize et al., 2018). Such distinct effects of "warmth/morality" and "competence/assertiveness" on antisocial behavior make it reasonable to deduce that people whose names connote lower warmth/morality but higher competence/assertiveness are more likely to commit crime.

\section{Overview of the Current Research}

Building on the past evidence, we proposed that criminal behavior may be predicted by four dimensions of name: (1) name popularity (an objective and physical dimension), (2) name valence (a subjective and evaluative dimension), (3) name warmth/morality (a socialcognitive dimension focusing on social functioning), and (4) name competence/assertiveness (a social-cognitive dimension focusing on goal pursuit). Specifically, we hypothesized that 
individuals with less popular, less positive, less warm/moral, but more competent/assertive names are more likely to commit crime. We also aimed to identify possibly distinct namecrime links for different crime categories and test whether these name dimensions could further predict the motive for intentionally committing crime.

The current research has several strengths over the past research. First, our study was based on a large-scale dataset of 981,289 criminals and their names, which ensured statistical power and the reliability of results. Second, we included and differentiated between a variety of crime categories, which covered property crime, violent crime, economic crime, and duty crime. Third, we measured four important dimensions of name, instead of testing only one name feature. Fourth, we controlled for necessary demographic variables, including gender, age, and education. Fifth, we tried to address as many alternative explanations as possible, including parental carelessness, family SES, and other geographic, familial, or genetic factors. Additionally, since we used Chinese criminals and Chinese names as the test case, the large diversity and the abundant connotations of Chinese names allowed us to measure name valence and name warmth-competence in a more meaningful way; the homogeneity of ethnic group within our sample also allowed us to implicitly control for possible ethnic effects. 


\section{Method}

\section{Data Collection}

\section{Criminal Cases}

We collected criminal cases from an official judicial website in China: The China Judgements Online (http://wenshu.court.gov.cn/). This website, launched in 2013, keeps a record of publicly available judgement documents since 2001 (Ma, Yu, \& He, 2016). The raw data on judgement documents were unstructured text, from which we used regular expression to automatically extract variables of the (first) accused: judgement year, trial procedure, type of the accused, number of the accused, full name, gender, birth year, education level, cause of action (i.e., reason of crime), and criminal punishment. ${ }^{1}$

Not all judgement documents were criminal judgement; many of them were irrelevant trial procedures (e.g., penalty alteration, withdrawal/dismissal of an appeal) without sufficient information about the criminal cases (Ma et al., 2016). To ensure the validity of analysis, we applied the following inclusion criteria: (1) trial procedure is "criminal judgement" (i.e., judged as criminal with a certain punishment); (2) type of the accused is "person" (i.e., not an organization or company); (3) number of the accused is one (i.e., not a group of criminals); (4) full name is available; and (5) age (= judgement year - birth year) is 16 80 years. These criteria left 981,289 criminals for analysis $\left(92.6 \%\right.$ male; $\left.M_{\text {age }}=38.08, S D_{\text {age }}=11.07\right)$. Their

\footnotetext{
${ }^{1}$ For cases with more than one criminal, only the information of first criminal was extracted because it would be more complex to extract and store multiple criminals for one case. Missing values in gender were imputed based on name gender ( $\mathrm{NG}$, a continuous variable ranging from -1 to 1 , indicating the difference in proportions of a name character used by males vs. females), because NG was highly correlated with individual gender $(r=.73, p<.001)$. We no longer treated NG as an independent predictor.
} 
educational backgrounds (with 170,679 missing values) were: $77.3 \%$ junior high school or below, $14.8 \%$ senior high school or technical secondary school, $4.9 \%$ junior college or higher vocational college, $2.8 \%$ bachelor's degree, and $0.2 \%$ master's degree or above.

\section{Non-Criminal Controls: A National Representative Sample}

The risk of individuals' criminal behavior cannot be validly estimated without an appropriate comparison group. An ideal comparison group for the criminal cases is a national representative sample of non-criminal "normal controls" with the same distributions of gender, age, and education as the Chinese population. To construct such a comparison group, we utilized a dataset of 3.2 million job-hunters collected from Ganji.com in previous research (Bao et al., 2020) and resampled 1 million cases from it by using stratified sampling.

According to the national statistics across gender, age groups, and education levels recorded in the 2010 China census (National Bureau of Statistics of China, 2010), we calculated stratum sample sizes required for a total of 1,000,000 cases (see Table S1) and performed stratified random sampling with replacement by using the R package sampling (Tillé \& Matei, 2016). This sample was representative of 16-to-65-year-old Chinese citizens: $50.9 \%$ male; $M_{\text {age }}=38.12, S D_{\text {age }}=13.35 ; 70.6 \%$ junior high school or below, $17.8 \%$ senior high school or technical secondary school, $6.8 \%$ junior college or higher vocational college, $4.5 \%$ bachelor's degree, and $0.4 \%$ master's degree or above. Their full names were available.

\section{Variables and Measures}

\section{Crime Variables}

Crime Categories. The crime data included seven major crime categories classified 
by the Criminal Law of the People's Republic of China: (1) violating property, (2) infringing personal rights, (3) endangering public security, (4) obstructing social management, (5) disrupting market economy, (6) embezzlement and bribery, and (7) dereliction of duty (for details, see Table 1). To note, three other crime categories - endangering national security, impairing the interests of national defense, and servicemen's transgression of duties-were not included because criminals' full names and cases' details were usually kept confidential in these categories, leaving extremely few available cases for analysis.

Criminal Motive (Intentional vs. Unintentional Crime). For Crime \#2 “infringing personal rights" and Crime \#3 “endangering public security", the Criminal Law differentiated between intentional and unintentional crime. Criminal behavior in the unintentional crime is usually unplanned, unexpected, and without a criminal motive. There were 12 pairs of crime subcategories in which the content of crime was matched but the intentionality was distinct (for details, see Table S2). This distinction allowed us to further analyze criminal motive and test whether name variables could predict the motive for committing crime.

\section{Name Variables}

Chinese Name Database. We processed Chinese names by using the R package ChineseNames, which contains a Chinese name database with national statistics for almost all surnames and given-name characters in China (Bao, 2020; Bao et al., 2020). This Chinese name database, covering 1.2 billion Han Chinese population (96.8\% of Han Chinese population born from 1930 to 2008 and still alive in 2008), includes 2,614 characters used in Chinese given names with their proportions in the Chinese population (separately for each 
gender and each birth cohort; i.e., pre-1960s, 1960-1969, 1970-1979, 1980-1989, 1990-1999, and 2000-2008) and 1,806 Chinese surnames with their proportions in the Chinese population (with no distinction of gender or birth cohort).

In this research, for simplicity, we refer to given name as "name" and family name as “surname". Five variables were included into analysis: name popularity and surname popularity were objective indices computed by actual frequency in naming practices; name valence, name warmth, and name competence were subjective indices judged by raters (for details, see below). For a given name with multiple characters, name variables was averaged across characters, which is a more feasible approach than rating millions of character combinations and has become a common research practice for handling Chinese names in such a large sample (Cai, Zou, Feng, Liu, \& Jing, 2018; see also Bao, 2020). ${ }^{2}$

Name Popularity (i.e., Name Commonness). Following previous research (Bao et al., 2020), we computed name popularity by using the formula:

$$
\mathrm{NP}=\log _{10}\left(\mathrm{PPM}_{\mathrm{character}}+1\right)
$$

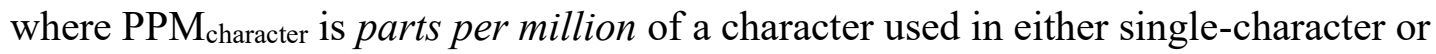
multi-character given names among the Han Chinese population within a specific birth decade. As an objective index, name popularity ranges from 0 to 4.82 .

\footnotetext{
${ }^{2}$ One may argue that “two negatives make a positive”. For example, the name “李莫愁” consists of a given name with two negative characters “莫” (don’t) and “愁” (worry) but the combination “莫愁” (don’t worry) has a positive meaning instead. We scrutinized the crime data but found only 17 such names: 孙补 堵, 岩不坎, 程无悔, 黄无缺, 李无忧, 卢忍敌, 张不停, 樊热闹, 李热闹, 冊抗旱, 张抗旱, 符老总, 李改命, 付追求, 江考验, 孙扶摇, 杜寄托. Therefore, this special situation was extremely rare in actual naming practices and unlikely to influence the results.
} 
Surname Popularity (i.e., Surname Commonness). In a way similar to the computation of name popularity, we computed surname popularity by using the formula:

$$
\mathrm{SNP}=\log _{10}\left(\mathrm{PPM}_{\text {surname }}+1\right)
$$

where $\mathrm{PPM}_{\text {surname }}$ is parts per million of a surname used by Han Chinese (birth cohort for surname was not differentiated in the Chinese name database). As an objective index, surname popularity ranges from 0 to 4.87 .

Name Valence (i.e., Positivity/Desirability of Character Meaning). To assess the basic evaluative dimension of name, we measured the valence (positivity vs. negativity) of given-name characters. We invited 16 Chinese raters ( 9 males and 7 females) to evaluate the valence $(1=$ strongly negative, $3=$ neutral, $5=$ strongly positive $)$ of all 2,614 given-name characters according to the meaning of each character. ${ }^{3}$ The interrater reliability for name valence was high $(\mathrm{ICC}=.921)$. We rescaled the valence scores from $1 \sim 5$ to $-2 \sim 2$, so that a score of 0 represents neutral meaning of name.

Name Warmth-Competence. To assess the two social-cognitive dimensions of name, we measured perceptions of warmth/morality and competence/assertiveness of givenname characters. According to the Stereotype Content Model (Fiske, 2018; Fiske et al., 2007), name warmth and name competence have been suggested to be two important socialcognitive dimensions of name (with a moderate inter-dimension correlation, $r=.42$; Newman et al., 2018). We adapted the rating task from previous research, with instruction presented as

\footnotetext{
3 Particularly, in the R package ChineseNames (Bao, 2020), we originally invited only 6 raters to evaluate name valence. To ensure the reliability of the valence score, we invited another 10 raters to complete the rating task, summing up to 16 raters. Note that the latter 10 raters also rated name warmth-competence.
} 
below (adapted from Newman et al., 2018; Chinese translations are shown in parentheses): According to psychological research, when people form impressions of others, they usually evaluate them in two aspects: warmth and competence.

・ “Warmth” (温暖) includes traits such as warm (热情), friendly (友好), righteous (正直), honest (诚实), kind (和善), fair (公平), sincere (真诚), reliable (可靠), and moral (有道德).

- “Competence” (能力) includes traits such as competent (能干), clever (聪 明), careful (细心), efficient (高效), creative (创新), ingenious (灵巧), knowledgeable (博学), persistent (坚韧), and intelligent (有智慧).

Imagine that you are about to meet a person whose given name contains each of the following characters. Please judge how likely he/she is to have traits related to "warmth" ("competence"). If you feel uncertain, please use your intuition and make your best guess.

We invited 10 Chinese raters ( 5 males and 5 females) to evaluate how likely a person whose name contains each of the 2,614 given-name characters is to have warmth- and competence-related traits $(1=$ strongly unlikely to have, $3=$ medium likelihood, $5=$ strongly likely to have). They completed the rating tasks separately for warmth and competence in sequence. In each task, we reminded raters of the meaning of warmth or competence by listing the specific traits as shown above. The interrater reliability for name warmth/morality $(\mathrm{ICC}=.774)$ and name competence/assertiveness $(\mathrm{ICC}=.712)$ were acceptable. Likewise, we rescaled both warmth and competence scores from 1 5 to $-2 \sim 2$. 


\section{Data Analysis}

To fully disclose the potential links between name and crime, we conducted analyses at both name (character) level and individual level (for descriptive statistics and correlations, see Table S3). The name-level analyses aimed to test whether the previous name-level finding about unpopular names and juvenile delinquency in the United States (Kalist \& Lee, 2009) could replicate in China and generalize to a broader range of criminal activities and name variables. The individual-level analyses aimed to test the name-crime links in a more rigorous way by using non-criminal controls and addressing a list of alternative explanations.

\section{Name-Level Analyses: Crime Risk Index (CRI)}

In the name-level analyses, we computed a "Crime Risk Index (CRI)" for each name character according to the percentage of a name character appearing in the crime data relative to the percentage of this character used in the Chinese population (i.e., relative risk ratio):

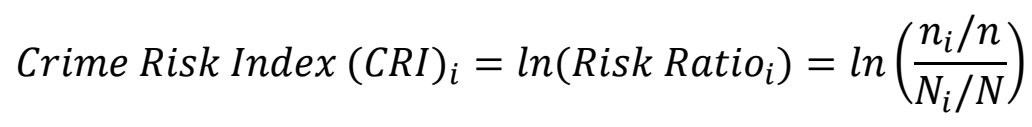

where $n_{i}$ is the number of criminals whose names contain the character $i, n$ is the total number of criminals (generally for all crime categories or specifically for one category), $N_{i}$ is the number of people in the Chinese population whose names contain the character $i$ (across all birth cohorts), and $N$ is the total number of people in the Chinese population. To control for a potential gender effect, we computed CRI based on the percentage of a name character appearing in the full crime dataset, the female subset, and the male subset, respectively (relative to that in the whole population, the female population, and the male population, respectively; see Figure 1 and Table 2). As the CRI was measured by log risk ratio (RR), it 
approximated to a normal distribution and can be easily interpreted: CRI $>0$ (i.e., RR $>1$ ) indicates that people with this name character are more likely to commit crime, whereas CRI $<0$ (i.e., $\mathrm{RR}<1$ ) indicates that people with this name character are less likely to commit crime. Those characters not appearing in the crime data were not included into analysis. Individual-Level Analyses: Criminal Cases vs. Non-Criminal Controls

In the individual-level analyses, to estimate the risk of individuals' criminal behavior, we used a national representative sample (i.e., the non-criminal controls), which had the same distributions of gender, age, and education as the Chinese population, as an appropriate comparison group for the criminal cases (for details, see Data Collection and Table S1). Following the research practice of pooling datasets of "cases" and "controls" to assess the effect of risk factors (e.g., Breslow \& Zhao, 1988; Grimes \& Schulz, 2005), we pooled the criminal cases $(n=981,289)$ and the non-criminal controls $(n=1,000,000)$ into one dataset and conducted logistic regression analyses. To examine the general name-crime links, we conducted binary logistic regression where the outcome was non-criminal (coded as 0) vs. criminal (coded as 1). To examine the specific name-crime links, we conducted multinomial logistic regression where the outcome was a factor variable indicating non-criminal controls (coded as "O") vs. criminal cases in the seven crime categories (coded from "X1" to "X7").

All data preprocessing and data analyses were conducted with R (R Core Team, 2020) in RStudio (RStudio Team, 2020), mainly using the R packages nnet (the "multinom" function for conducting multinomial logistic regression; Venables \& Ripley, 2002) and bruceR (Bao, 2019). R code is available at Open Science Framework (https://osf.io/s2rgz/). 


\section{Results}

\section{Name-Crime Links: Do Names Predict Criminal Behavior?}

At the name level, simple correlation analyses $(N=2,470$ name characters $)$ showed that the CRI was negatively correlated with name popularity $(r=-.61, p<.001,95 \% \mathrm{CI}$ $[-.63,-.58])$, name valence $(r=-.53, p<.001,95 \% \mathrm{CI}[-.55,-.50])$, name warmth/morality $(r=-.50, p<.001,95 \% \mathrm{CI}[-.53,-.47])$, and name competence/assertiveness $(r=-.29, p$ $<.001,95 \%$ CI $[-.32,-.25])$. When including all name variables into one regression model (Table 2, Model 1), we found that a higher crime risk was predicted by possessing a less popular name $(\beta=-.42, p<.001,95 \%$ CI $[-.46,-.38])$, a less positive name $(\beta=-.26, p$ $<.001,95 \%$ CI $[-.32,-.19])$, a less warm/moral name $(\beta=-.16, p<.001,95 \%$ CI $[-.21$, $-.11])$, but a more competent/assertive name $(\beta=.17, p<.001,95 \%$ CI $[.12, .21])$; these patterns held consistent for almost all crime categories (Table 2, Models 2-8). ${ }^{4}$

Then, we controlled for a potential gender effect by testing the name-crime links in female and male subsets, respectively. For females, the CRI was predicted by lower name

\footnotetext{
${ }^{4}$ Besides the name variables, we also examined the surname-level relation between surname popularity and CRI. A total of 1,202 surnames appeared in the criminal cases and thus were included into analysis. Similar to the finding of given names, possessing an unpopular surname was correlated with a higher CRI $(r=-.78, p<.001,95 \% \mathrm{CI}[-.80,-.75])$. However, we suspected that such a high correlation was spurious because (1) there was a serious problem of heteroscedasticity among Chinese surnames (i.e., those popular surnames had lower variation of CRI, whereas those unpopular surnames had higher variation of CRI); and (2) the scatterplot showed that the relationship between surname popularity and CRI was not linear and the CRI among unpopular surnames seemed to be spuriously high. These problems were likely due to the fact that the diversity of surnames is quite limited in China (even the top 25 popular Chinese surnames have covered about $60 \%$ of the Chinese population; see Bao et al., 2020). Therefore, we refrained from making conclusions about surname popularity. Note that all these problems did not exist among given names.
} 
popularity $(\beta=-.65, p<.001,95 \% \mathrm{CI}[-.69,-.60])$ and lower name warmth/morality $(\beta=$ $-.14, p<.001,95 \% \mathrm{CI}[-.20,-.08])$, whereas name valence and competence/assertiveness did not predict CRI (Table 2, Models 9-16). For males, the CRI was predicted by lower name popularity $(\beta=-.49, p<.001,95 \%$ CI $[-.53,-.45])$, lower name valence $(\beta=-.12, p<.001$, $95 \%$ CI $[-.19,-.06])$, and lower name competence/assertiveness $(\beta=-.17, p<.001,95 \% \mathrm{CI}$ $[-.21,-.12]$ ), whereas name warmth/morality was not associated with CRI (Table 2, Models 17-24). Furthermore, we scrutinized the name-crime links by mapping them onto surface plots: those name characters with relatively high CRI were identified to be unpopular, negative, and cold/immoral characters (Figure 1A-1F), whereas the relation between crime risk and competent/assertive names existed only for males (Figure 1F). More intriguingly, for relatively positive names, the link between name popularity and the CRI disappeared (Figure $1 \mathrm{~A}, 1 \mathrm{C}, 1 \mathrm{E})$, suggesting that the detrimental effect of possessing an uncommon name may be compensated for by positive name meaning in China.

Overall, these name-level results replicated and extended the previous name-level finding about name popularity and juvenile delinquency (Kalist \& Lee, 2009). Specifically, possessing an unpopular, undesirable, and cold/immoral name predicted a higher crime risk. However, the name-level analyses could not control for confounding factors and alternative explanations. To address these issues and examine the name-crime links in a more rigorous way, we conducted individual-level analyses, where we used a national representative sample of non-criminal controls $(n=1,000,000)$ as a comparison group for the criminal cases $(n=$ $981,289)$ to test whether name variables could predict individuals' risk of criminal behavior. 
The individual-level binary logistic regression showed that people with less popular names $(b=-0.217, S E=0.002, z=-89.86, p<.001)$, less popular surnames $(b=-0.061, S E$ $=0.002, z=-31.71, p<.001)$, less positive names $(b=-0.147, S E=0.004, z=-37.13, p$ $<.001)$, and less warm/moral names $(b=-0.630, S E=0.005, z=-120.44, p<.001)$ but more competent/assertive names $(b=0.991, S E=0.006, z=179.25, p<.001)$ were more likely to commit crime in general (Table 3, Models 1-5), which resembled the name-level findings. When including all these name variables and controlling for gender, age, and education, we observed smaller but still significant prediction effects of name popularity $(b=-0.064, S E=$ $0.003, z=-18.79, p<.001)$, surname popularity $(b=-0.065, S E=0.002, z=-28.29, p$ $<.001)$, name warmth/morality $(b=-0.120, S E=0.008, z=-14.90, p<.001)$, and name competence/assertiveness $(b=0.037, S E=0.008, z=4.66, p<.001)$, whereas the effect of name valence got unexpectedly reversed (Table 3 , Model 6). ${ }^{5}$

To identify the potential differences of name-crime links between crime categories, we conducted multinomial logistic regression to test name variables (separately or jointly) with demographic variables controlled or not (Tables 4-5). The seven major crime categories (see Table 1) can be further classified into property crime (Crime \#1), violent crime (Crime \#2-4), economic crime (Crime \#5-6), and duty crime (Crime \#7). Results of demographic variables showed that (1) males were more likely to commit all types of crime; (2) younger people were more likely to commit property and violent crime but less likely to commit

\footnotetext{
5 The reverse (from negative to positive) of the effect of name valence may result from multicollinearity. Among all predictors, the VIF (variance inflation factor) of name valence was the largest (VIF $=3.50$ ), albeit not exceeding the threshold of 5 , whereas the VIFs of all the other predictors were lower than 2 .
} 
economic and duty crime; and (3) people with lower education level were more likely to commit property and violent crime, whereas people with higher education level were more likely to commit economic and duty crime (Table 5, Model 5). These results make sense and are consistent with previous findings (e.g., Andrews \& Bonta, 2010; Bartol \& Bartol, 2017; Durrant, 2018). Indeed, for example, only when a person reached a high level of education and became a public official or a government employee can they have the chance to commit economic or duty crime. Additionally, these findings help justify the practice of conducting logistic regression on the pooled datasets of criminal cases and non-criminal controls.

After controlling for the effects of gender, age, and education, we observed distinct prediction effects of name variables on different categories of criminal behavior. Possessing an unpopular name predicted a higher risk of committing property and violent crime but a lower risk of committing economic and duty crime (Table 5, Model 1). Possessing an unpopular surname predicted a higher risk of committing property, violent, and economic crime but not duty crime (Table 5, Model 2). Bearing a name with negative meaning predicted a higher risk of property and violent crime but a lower risk of economic crime (Table 5, Model 3). Name warmth/morality negatively predicted property and violent crime, whereas name competence/assertiveness positively predicted violent and economic crime (Table 5, Model 4). Most of these results remained when including all predictors into one model (Table 5, Model 5). More importantly, the two social-cognitive dimensions of namewarmth and competence — had distinct patterns (opposite directions) in predicting criminal behavior, which was observed in most crime categories (Table 5; see also Figure 2). 
In summary, both name-level and individual-level analyses have replicated the prior finding on the link between unpopular names and juvenile delinquency (Kalist \& Lee, 2009) and extended the name-crime links to a basic evaluative dimension (name valence) and two social-cognitive dimensions (name warmth/morality and name competence/assertiveness). More critically, beyond the simple valence of name, we have revealed the differentiated effects of name warmth-competence in both terms of prediction directions and crime categories. Individuals whose names imply low warmth/morality (e.g., cold, unfriendly, dishonest, unreliable, immoral) were more likely to commit violent and property crime, whereas individuals whose names imply high competence/assertiveness (e.g., competent, clever, careful, creative, persistent) were more likely to commit violent and economic crime. The name-crime links were statistically reliable and not reducible to demographic confounds such as gender and education.

\section{Addressing Alternative Explanations}

Although the name-crime links likely did not suffer from reverse causality (i.e., crime causing name), the correlational nature of our data might make the name-crime links prone to omitted-variable bias. Even though we have controlled for several demographic confounds, we could not rule out all potential alternative explanations. It was still possible that some omitted third variables related to one's parents, family background, or other factors made the name-crime links spurious. Here we try to address three plausible candidates of alternative explanations and test the robustness of the name-crime links.

\section{Alternative Explanation 1: Parental Carelessness}


Careless parents may manifest both careless naming (i.e., choosing a negative name for their children) and careless upbringing (i.e., bringing up their children in a negative way) (cf. Gebauer et al., 2012; Twenge \& Manis, 1998), and such parental carelessness would apparently increase children's crime risk. However, parental carelessness was not likely to explain the effects of name popularity and surname popularity, because the uniqueness vs. commonness of given names is mainly a product of social taste (Lieberson \& Bell, 1992) and cultural change (Cai, Huang, \& Jing, 2019) and the uniqueness vs. commonness of surnames cannot be altered by parents. Indeed, careless parents may give their baby either a common name due to effortlessness or a unique name due to arbitrariness. Thus, such an alternative account by parental carelessness may only confound the effect of name valence but not the effect of name or surname popularity.

\section{Alternative Explanation 2: Family Socioeconomic Status (SES)}

People living in poor regions and rural areas in China used to endorse a folk belief that “giving children a negative name makes it easier to feed them” (“起个贱名好养活”), because they believed that ghosts did not like people with a negative name and thus would not easily bring them death (Fei, 1939; Ma, 1997). Hence, parents in poor or low-SES family, which constitutes a risk factor for children's criminal behavior, may give a negative name to their children on purpose (without being aware of its negative impact).

We addressed this alternative explanation by testing a potential moderating effect of social change on the name-crime link. Ever since 1980s, when China's One-Child Policy and the Reform and Opening-Up Policy were implemented, rural people in China have faced less 
difficulties in feeding their children, so that the aforementioned folk belief has become less prevalent (Ma, 1997). If this alternative account was the case, then name negativity would have a smaller effect on predicting criminal behavior as the times progress. However, results did not support this alternative account: we regressed criminal cases vs. non-criminal controls on name valence, gender, education, birth year, and the interaction between name valence and birth year (both were mean-centered), finding that the effect of name valence was moderated by birth year in an opposite direction $\left(b_{\text {moderation }}=-0.012, S E=0.000, z=-31.99, p<.001\right)$. In particular, the Johnson-Neyman (J-N) technique for probing simple slopes showed that name valence began to negatively predict crime at birth year $1981.24\left(b_{\mathrm{J}-\mathrm{N}}=-0.009, S E=\right.$ $0.005, z=-1.96, p=.050)$ and yielded the largest effect when birth year reached the maximum in the present data at $2002\left(b_{\mathrm{J}-\mathrm{N}}=-0.261, S E=0.010, z=-27.01, p<.001\right)$. This result was opposite to the direction that the alternative explanation by family SES predicted.

\section{Alternative Explanation 3: Geographic, Familial, and Genetic Factors}

Although our data did not record information about individuals' geographic regions, familial histories, or genetic features, we may naturally control for some geographic, familial, or genetic factors by analyzing people with the same surname-especially a surname with a concentrated geographic distribution and a congenetic inheritance history. In China, people with the same surname Kong (“孔”) can be a suitable test case for such a controlled analysis. Genetic evidence has shown that people with the surname Kong, who are mostly traceable from and living in Shandong province, are likely to have the same ancestor (Hou, Wang, Jiang, Liu, \& Li, 2016). Furthermore, one common practice among the Kong family is the use 
of generation name (“辈分名”) as a part of given name (usually the first character of a given name; Zhu \& Millward, 1987). Hence, to differentiate between "generational” given name (i.e., the first character) and "personal" given name (i.e., the second character), we included individuals whose given name consists of two characters into analysis. Given that "personal" given name is more symbolic and distinctive for a person than "generational" given name, we predicted that the name-crime links would be more pronounced for "personal" given name than for "generational" given name.

We conducted binary logistic regression where the outcome was criminal cases vs. non-criminal controls with the same surname Kong. We also differentiated between the first and second character of given names for all name variables (Table S4). Results showed that both the valence of "personal" given name $(b=-0.423, S E=0.113, z=-3.74, p<.001)$ and the warmth/morality of "personal" given name $(b=-0.486, S E=0.139, z=-3.48, p<.001)$ negatively predicted criminal behavior, whereas the other name features could not predict crime (Table S4, Models 1-3). When considering all name variables jointly and controlling for all demographic variables, the warmth/morality of "personal" given name still negatively predicted crime $(b=-0.452, S E=0.225, z=-2.01, p=.044)$, whereas name valence was no longer predictive (Table S4, Model 4). Multinomial logistic regression further showed that lower warmth/morality of "personal" given name specifically predicted a higher risk of committing violent crime (Crime \#2): $b=-0.901, S E=0.362, z=-2.49, p=.013$.

\section{Criminal Motive Analysis: Do Names Predict Intentionally Committing Crime?}

The above analyses have provided convergent evidence that criminal behavior can be 
predicted by certain name features, especially by name warmth/morality—one of the two fundamental dimensions in social cognition. Nonetheless, these results could not address an important psychological factor in criminal behavior: criminal motive. A criminal activity has both legal meaning and psychological significance. A motivated or planned criminal activity is apparently less moral and less tolerable than an unmotivated or unplanned criminal activity. Hence, it is necessary to differentiate between intentional and unintentional crime and examine whether name features could predict the intention of committing crime.

The Criminal Law of China differentiated between intentional and unintentional crime for 12 pairs of crime subcategories in Crime \#2 “infringing personal rights" and Crime \#3 "endangering public security" (Table S2), in which the content of crime was matched but the intentionality was distinct. This subset of data involved 108,141 intentional-crime cases and 5,309 unintentional-crime cases. Hence, we preformed binary logistic regression where the outcome was intentional vs. unintentional crime (Table 6). Possessing a cold/immoral name robustly predicted criminal motive (Table 6 , Models $4-5 ; p s<.001$ ), which remained significant $(b=-0.217, S E=0.079, z=-2.73, p=.006)$ after controlling for gender, age, and education (Table 6, Model 6). Lower name warmth/morality still predicted the intention of committing crime when controlling for the fixed effect of the two crime categories (name warmth/morality: $b=-0.206, S E=0.083, z=-2.50, p=.013)$ or the 12 pairs of crime subcategories (name warmth/morality: $b=-0.192, S E=0.091, z=-2.12, p=.034$ ). In contrast, the other features of name could not predict criminal motive (Table 6, Model 6). 


\section{Discussion}

By analyzing a large archival dataset of 981,289 Chinese criminals across seven crime categories and four name dimensions, the current research presents convergent evidence that possessing a "bad" name can be a risk factor for criminal behavior (as compared to the whole Chinese population and a national representative sample of $1,000,000$ non-criminal controls). In general, people with unpopular, negative, less warm/moral, but more competent/assertive names were more likely to commit crime. Specifically, the name-crime links were distinct between different crime categories - possessing an unpopular, negative, or cold/immoral name predicted property and violent crime, whereas possessing a competent/assertive name predicted violent and economic crime. Most of these name-crime links held true after controlling for demographic confounds. When further addressing geographic, familial, and genetic factors by conducting a focused analysis on people with the same surname Kong, we identified that lower warmth/morality of "personal" given name (rather than "generational" given name) robustly predicted criminal behavior, especially for violent crime. Moreover, in a matched-crime analysis, where the content of crime was matched but the intentionality of crime was differentiated, we found robust evidence that lower name warmth/morality could also predict the motive for intentionally committing crime.

Our findings were statistically reliable due to large sample size and rigorous methods. We not only replicated the past finding about the link between name popularity and juvenile delinquency (Kalist \& Lee, 2009) but also extended the name-crime links to other important dimensions of name and to a broader categories of crime. Critically, as we controlled for a set 
of sociodemographic factors, the name-crime links were not reducible to such confounding factors. More intriguingly, name warmth/morality_one crucial dimension of name that focuses on social functioning and the "communal content" in social cognition — could predict both the motive for committing crime and the risk of actual criminal behavior.

There are many psychological mechanisms that may account for the current findings. First, from the perspective of implicit egotism, people with bad names may be more likely to do bad things because of the similarity of "badness" between their name and their behavior (cf. Pelham, Mirenberg, \& Jones, 2002). Second, from the perspective of moral identity development, the name-crime links may result from weaker morality among people with less warm/moral names, because an immoral name may serve as a reminder of unethical self, which may hinder the construction of moral identity early in adolescence (cf. Boegershausen, Aquino, \& Reed, 2015; Hardy \& Carlo, 2011). Third, from the perspective of mental health, the name-crime links may be due to maladaptive psychosocial functioning among people with negative or cold/immoral names, because people with a negative name have lower selfesteem, worse mental health, and less education (e.g., Gebauer et al., 2012; Twenge \& Manis, 1998). Fourth, from the perspective of peer influence, the name-crime links can also be partly due to an observer effect (i.e., interpersonal neglect or peer rejection toward those bad-name bearers). For instance, people with unpopular and undesirable names are less liked and more negatively treated in job-recruitment and online-dating contexts (Cotton et al., 2008; Gebauer et al., 2012; Pascual et al., 2015), which may contribute to a higher risk of criminal behavior among those bad-name bearers. 
However, we recognize that these interpretations are not likely the only mechanisms linking bad names to criminal behavior. There might be some alternative explanations. Even though we have accounted for demographic control variables (gender, age, education), where individuals' education level can be a proxy for some omitted variables, future research should directly control for some other confounding variables that we did not address here. Moreover, we are limited in making causal inference on the name-crime links. Indeed, it is impractical and unethical to randomly assign babies different names at birth and test whether this random assignment is sufficient to cause criminal behavior when they grow up. Our findings are only correlational and cannot be regarded as causal evidence. Nevertheless, if future research were to observe a causal effect of name on some forms of unethical behavior (cf. Lu, Lee, Gino, \& Galinsky, 2018), researchers could be more confident to draw causal inference.

Despite some limitations, the present research has notable theoretical contributions. First, it has uncovered the real-world ethical costs of bearing bad names. By testing a broad range of crime categories and a variety of name dimensions, our findings extend the dark side of name effects from mental health, interpersonal, and educational domains to a much more serious domain: crime. Second, our findings advance the past finding about the link between name popularity and juvenile delinquency (Kalist \& Lee, 2009)—we have revealed different patterns of name-crime links for different crime categories and demonstrated distinct effects of name warmth and name competence on predicting various types of criminal behavior. Third, by using Chinese as a test case, we address the cross-cultural generalizability of the detrimental effects of bad names on life outcomes. Fourth, we contribute to the social 
cognition literature by showing how the two fundamental dimensions of content in social cognition are associated with human behavior (Abele \& Wojciszke, 2014, 2019; Fiske, 2018). In particular, we present evidence that if people's names imply lower warmth/morality, they are more likely to have a criminal motive and actually commit criminal behavior. Overall, our findings connect the fields of names, social cognition, criminology, and moral psychology.

The current findings also have important practical implications. For parents who are going to name their newborns, it is crucial to consider a socially desirable and warm/moral name. Parents across Western and Eastern cultures have become more likely to give a unique name to their children (e.g., Cai et al., 2018; for a review, see Cai et al., 2019). This naming practice, however, is a double-edged sword. On the one hand, possessing a unique name can help satisfy one's need for uniqueness and sometimes can be beneficial to one's career achievement in certain jobs (Bao et al., 2020). On the other hand, because unique names are often rated as negative or cold/immoral, some unpopular names may relate to negative life outcomes, as shown in the current research and the past research (e.g., Gebauer et al., 2012; Kalist \& Lee, 2009). Therefore, besides considering name uniqueness, parents should also pay much attention to both name valence and name warmth/morality and avoid choosing those "peculiar" (i.e., unique but undesirable or immoral) names.

In conclusion, names matter for human morality. Possessing a bad name (especially a name implying lower warmth/morality) predicts both the motive for committing crime and the risk of criminal behavior in real life. Though not the only factor relevant to crime, bad names can invite trouble. 


\section{Acknowledgments}

This research was supported by National Social Science Fund of China (17ZDA324) and National Natural Science Foundation of China (71603014). We thank Yiming Jing, Delin Sun, Zenan Dou, and Yue Wu for their useful comments on this research.

\section{Author Contributions}

H.C., J.W., and H.-W.-S.B. designed the research; J.W. and H.-W.-S.B. collected the data; H.-W.-S.B. and J.W. analyzed the data; and H.-W.-S.B., H.C., and J.W. wrote the paper.

\section{Conflict of Interest}

The author(s) declared no potential conflicts of interest with respect to the research, authorship, and/or publication of this article.

\section{Open Practices}

The $\mathrm{R}$ code for the analyses in this research is available at Open Science Framework (https://osf.io/s2rgz/). The Chinese name database we used in this research is available at GitHub (https://github.com/psychbruce/ChineseNames). The raw data of criminal cases are not publicly available according to a confidentiality agreement. 


\section{References}

Abele, A. E., \& Wojciszke, B. (2014). Communal and agentic content in social cognition: A dual perspective model. Advances in Experimental Social Psychology, 50, 195-255.

Abele, A. E., \& Wojciszke, B. (Eds.). (2019). Agency and communion in social psychology. New York, NY: Routledge.

Andrews, D. A., \& Bonta, J. (2010). The psychology of criminal conduct (5th. ed.). New Providence, NJ: Anderson Publishing.

Assink, M., van der Put, C. E., Hoeve, M., de Vries, S. L. A., Stams, G. J. J. M., \& Oort, F. J. (2015). Risk factors for persistent delinquent behavior among juveniles: A meta-analytic review. Clinical Psychology Review, 42, 47-61.

Bao, H.-W.-S. (2019). bruceR: Broadly useful collections and extensions of R functions. R package version 0.4.0. https://github.com/psychbruce/bruceR

Bao, H.-W.-S. (2020). ChineseNames: Chinese name database 1930-2008. R package version 0.4.0. https://github.com/psychbruce/ChineseNames

Bao, H.-W.-S., Cai, H., DeWall, C. N., Gu, R., Chen, J., \& Luo, Y. L. L. (2020). Name uniqueness predicts career choice and career achievement. Preprint at PsyArXiv https://doi.org/10.31234/osf.io/53j86

Bartol, C. R., \& Bartol, A. M. (2017). Criminal behavior: A psychological approach (11th ed.). England, UK: Pearson Education.

Besemer, S., Ahmad, S. I., Hinshaw, S. P., \& Farrington, D. P. (2017). A systematic review and meta-analysis of the intergenerational transmission of criminal behavior. Aggression and Violent Behavior, 37, 161-178.

Boegershausen, J., Aquino, K., \& Reed, A., II. (2015). Moral identity. Current Opinion in Psychology, 6, 162-166.

Breslow, N. E., \& Zhao, L. P. (1988). Logistic regression for stratified case-control studies. Biometrics, 44(3), 891-899.

Busse, T. V., \& Seraydarian, L. (1978). The relationships between first name desirability and school readiness, IQ, and school achievement. Psychology in the Schools, 15(2), 297302.

Busse, T. V., \& Seraydarian, L. (1979). First names and popularity in grade school children. Psychology in the Schools, 16(1), 149-153.

Cacioppo, J. T., \& Berntson, G. G. (1994). Relationship between attitudes and evaluative space: A critical review, with emphasis on the separability of positive and negative substrates. Psychological Bulletin, 115(3), 401-423.

Cai, H., Huang, Z., \& Jing, Y. (2019). Living in a changing world: The change of culture and psychology. In D. Matsumoto \& H. C. Hwang (Eds.), The handbook of culture and psychology (2nd ed., pp. 786-817). New York, NY: Oxford University Press.

Cai, H., Zou, X., Feng, Y., Liu, Y., \& Jing, Y. (2018). Increasing need for uniqueness in contemporary China: Empirical evidence. Frontiers in Psychology, 9, 554.

Cotton, J., O’Neill, B. S., \& Griffin, A. (2008). The "name game": Affective and hiring reactions to first names. Journal of Managerial Psychology, 23(1), 18-39. 
Durrant, R. (2018). An introduction to criminal psychology (2nd ed.). New York, NY: Routledge.

Erwin, P. G. (1993). First names and perceptions of physical attractiveness. Journal of Psychology, 127(6), 625-631.

Fei, X.-T. (1939). Peasant life in China: A field study of country life in the Yangtze valley. London: Routledge.

Fiske, S. T. (2018). Stereotype content: Warmth and competence endure. Current Directions in Psychological Science, 27(2), 67-73.

Fiske, S. T., Cuddy, A. J. C., \& Glick, P. (2007). Universal dimensions of social cognition: Warmth and competence. Trends in Cognitive Sciences, 11(2), 77-83.

Gard, A. M., Dotterer, H. L., \& Hyde, L. W. (2019). Genetic influences on antisocial behavior: Recent advances and future directions. Current Opinion in Psychology, 27, $46-55$.

Garwood, S. G. (1976). First-name stereotypes as a factor in self-concept and school achievement. Journal of Educational Psychology, 68(4), 482-487.

Gebauer, J. E., Leary, M. R., \& Neberich, W. (2012). Unfortunate first names: Effects of name-based relational devaluation and interpersonal neglect. Social Psychological and Personality Science, 3(5), 590-596.

Grimes, D. A., \& Schulz, K. F. (2005). Compared to what? Finding controls for case-control studies. Lancet, 365(9468), 1429-1433.

Harari, H., \& McDavid, J. W. (1973). Name stereotypes and teachers' expectations. Journal of Educational Psychology, 65(2), 222-225.

Hardy, S. A., \& Carlo, G. (2011). Moral identity. In S. J. Schwartz, K. Luyckx, \& V. L. Vignoles (Eds.), Handbook of identity theory and research (pp. 495-513). New York, NY: Springer.

Hou, W.-G., Wang, C.-C., Jiang, S.-H., Liu, H.-D., \& Li, H. (2016). 曲阜地区孔姓人群 17 个 Y-STR 基因座遗传多态性分析 [Genetic diversity of seventeen Y-STR loci among the people with the surname Kong from Qufu Prefecture] (in Chinese). Acta Anthropologica Sinica, 35(1), 125-131.

Jones, S. E., Miller, J. D., \& Lynam, D. R. (2011). Personality, antisocial behavior, and aggression: A meta-analytic review. Journal of Criminal Justice, 39(4), 329-337.

Kalist, D. E., \& Lee, D. Y. (2009). First names and crime: Does unpopularity spell trouble? Social Science Quarterly, 90(1), 39-49.

Lieberson, S., \& Bell, E. O. (1992). Children's first names: An empirical study of social taste. American Journal of Sociology, 98(3), 511-554.

Lu, J. G., Lee, J. J., Gino, F., \& Galinsky, A. D. (2018). Polluted morality: Air pollution predicts criminal activity and unethical behavior. Psychological Science, 29(3), 340355.

Ma, C., Yu, X.-H., \& He, H.-B. (2016). 大数据分析：中国司法裁判文书上网公开报告 [Big data analysis: A report on the online publicity of judicial documents of China] (in Chinese). China Law Review, (4), 195-246.

Ma, X.-S. (1997). 正在悄悄变化的农村人名 [The quietly changing personal names of rural 
people] (in Chinese). Society, (12), 16-17.

McDavid, J. W., \& Harari, H. (1966). Stereotyping of names and popularity in grade-school children. Child Development, 37(2), 453-459.

National Bureau of Statistics of China. (2010). 2010 population census of China (Table A0401, “全国分年龄、性别、受教育程度的 6 岁及以上人口”). http://www.stats.gov.cn/tjsj/pcsj/rkpc/6rp/excel/A0401a.xls

Newman, L. S., Tan, M., Caldwell, T. L., Duff, K. J., \& Winer, E. S. (2018). Name norms: A guide to casting your next experiment. Personality and Social Psychology Bulletin, 44(10), 1435-1448.

Pascual, A., Guéguen, N., Vallée, B., Lourel, M., \& Cosnefroy, O. (2015). First name popularity as predictor of employability. Names, 63(1), 30-36.

Pelham, B. W., Mirenberg, M. C., \& Jones, J. T. (2002). Why Susie sells seashells by the seashore: Implicit egotism and major life decisions. Journal of Personality and Social Psychology, 82(4), 469-487.

R Core Team. (2020). R: A language and environment for statistical computing. R Foundation for Statistical Computing, Vienna, Austria. https://www.r-project.org/

RStudio Team. (2020). RStudio: Integrated development environment for R. https://rstudio.com/

Tillé, Y., \& Matei, A. (2016). sampling: Survey sampling. R package version 2.8. https://cran.r-project.org/package=sampling

Twenge, J. M., \& Manis, M. (1998). First-name desirability and adjustment: Self-satisfaction, others' ratings, and family background. Journal of Applied Social Psychology, 28(1), $41-51$.

Venables, W. N., \& Ripley, B. D. (2002). Modern applied statistics with S (4th ed.). New York, NY: Springer.

Vize, C. E., Miller, J. D., \& Lynam, D. R. (2018). FFM facets and their relations with different forms of antisocial behavior: An expanded meta-analysis. Journal of Criminal Justice, 57, 67-75.

Zhu, B., \& Millward, C. (1987). Personal names in Chinese. Names, 35(1), 8-21. 


\section{Figures}

(1) Full dataset (involving 2,470 name characters)

A

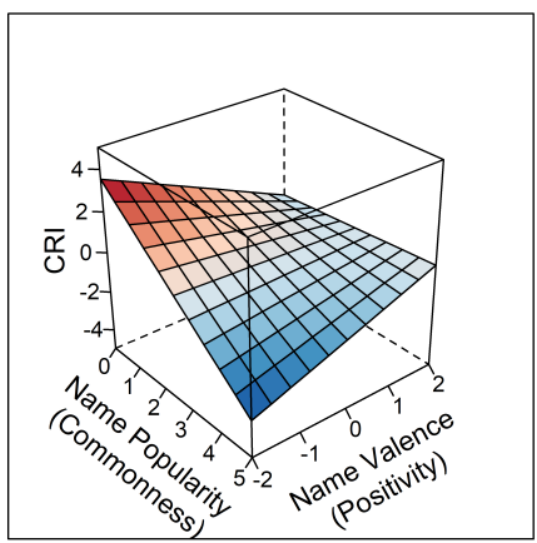

B

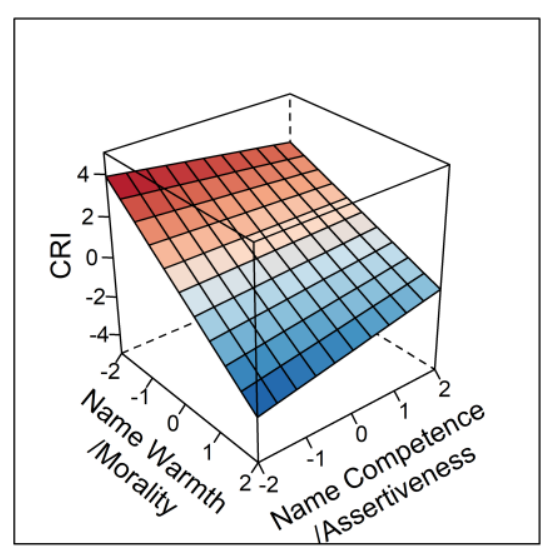

(2) Female subset (involving 1,734 name characters)

C

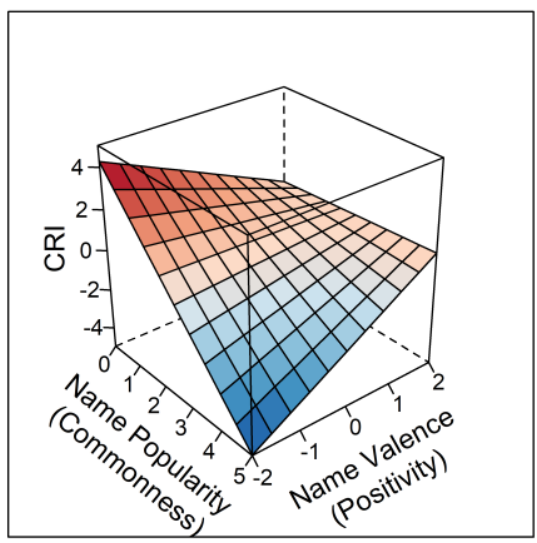

D

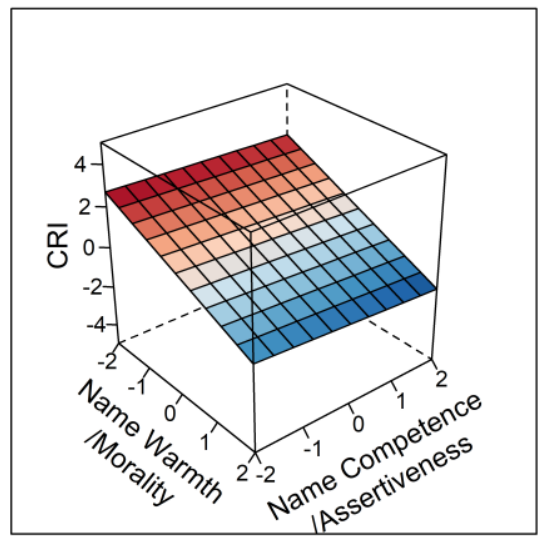

(3) Male subset (involving 2,442 name characters)

E

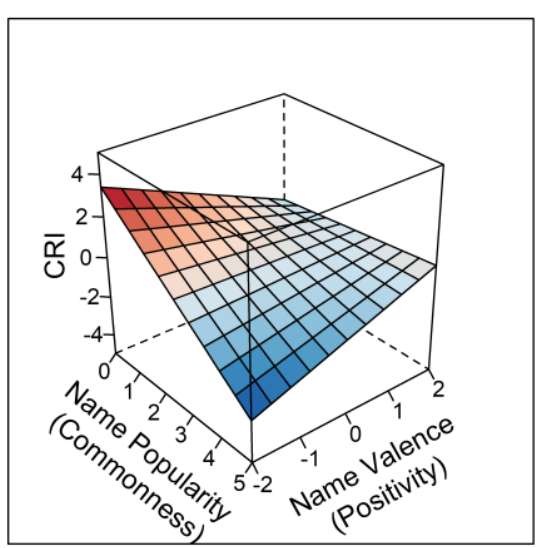

$\mathbf{F}$

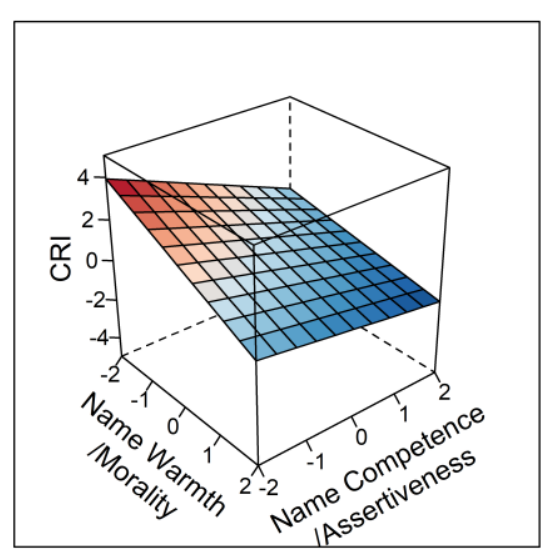

Figure 1. Surface Plots of Name-Level Links Between Name Variables and Crime Risk Index (CRI).

The CRI is measured as "log risk ratio" according to the percentage of a name character appearing in the crime data (full dataset / female subset / male subset) relative to the percentage of the character used in the Chinese population (whole population / female population / male population). 

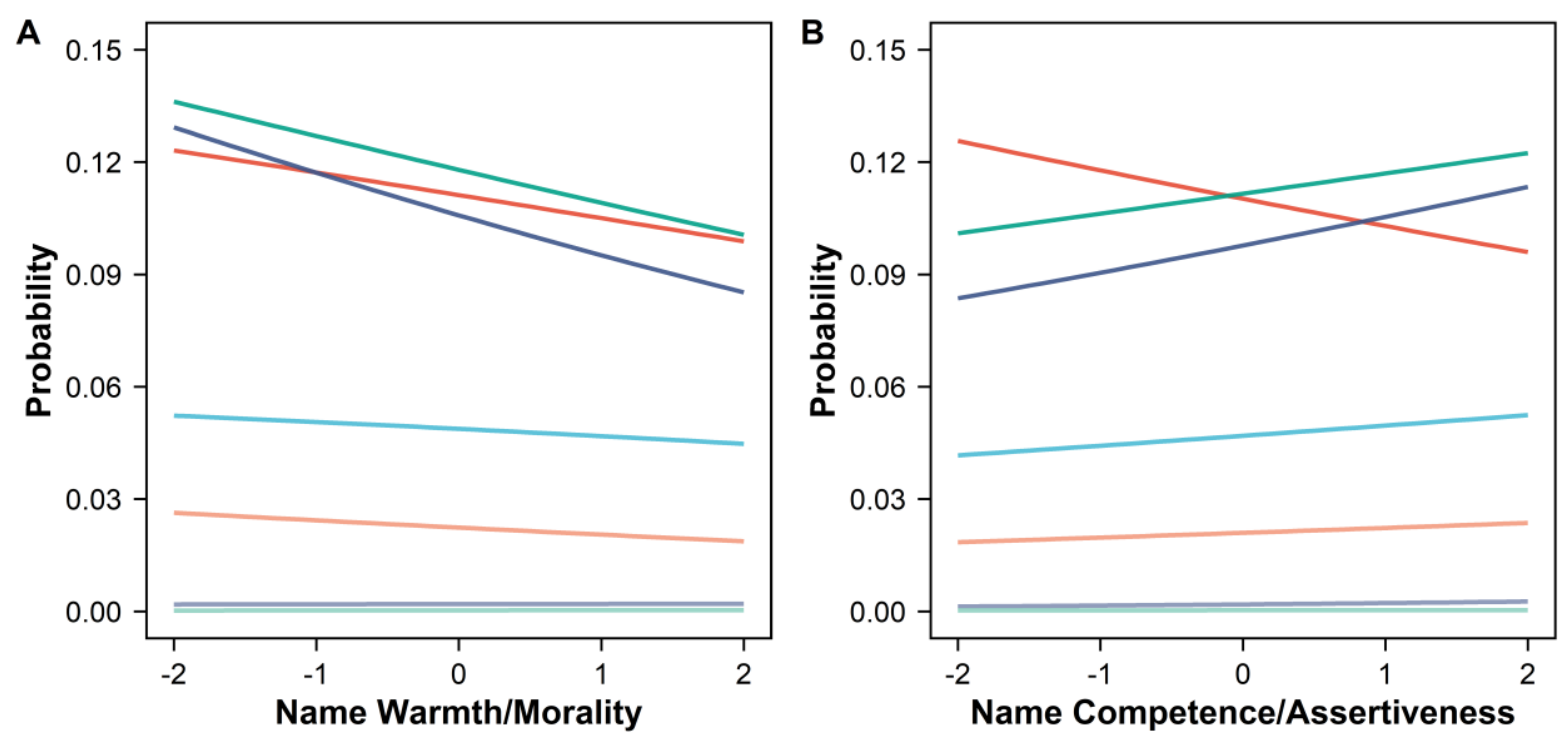

- Crime \#1: Violating property

- Crime \#5: Disrupting market economy

- Crime \#2: Infringing personal rights

- Crime \#6: Embezzlement and bribery

- Crime \#3: Endangering public security

- Crime \#4: Obstructing social management

Figure 2. Individual-Level Probability of Criminal Behavior for Seven Major Crime Categories Predicted by Name Warmth/Morality and Name Competence/Assertiveness.

Fitting curves display the probability estimated by multinomial logistic regression (see Table 5, Model 5). Gender, age, education, and other name variables were controlled and fixed at their mean values. 


\section{Tables}

Table 1. Seven Major Crime Categories in China.

\begin{tabular}{|c|c|c|}
\hline Crime category & Most frequent subtypes & $N$ \\
\hline $\begin{array}{l}\text { \#1: Violating property } \\
\text { (侵犯财产) }\end{array}$ & $\begin{array}{l}\text { larceny (盗窃); fraud (许骗); robbery (抢劫); extortion (敲诈 } \\
\text { 勒索) }\end{array}$ & 284,884 \\
\hline $\begin{array}{l}\text { \#2: Infringing personal rights } \\
\text { (侵犯公民人身权利) }\end{array}$ & $\begin{array}{l}\text { assault (故意伤害); murder (故意杀人); abduction (绑架); } \\
\text { rape (强奸) }\end{array}$ & 119,623 \\
\hline $\begin{array}{l}\text { \#3: Endangering public security } \\
\text { (危害公共安全) }\end{array}$ & $\begin{array}{l}\text { dangerous driving (危险驾驶); traffic offence (交通肇事); } \\
\text { possessing guns (持枪); arson (放火) }\end{array}$ & 313,784 \\
\hline $\begin{array}{l}\text { \#4: Obstructing social management } \\
\text { (妨害社会管理秩序) }\end{array}$ & $\begin{array}{l}\text { drug manufacturing/trafficking (制造、贩卖毒品); picking } \\
\text { quarrels (寻畔滋事); gambling (赌博) }\end{array}$ & 203,624 \\
\hline $\begin{array}{l}\text { \#5: Disrupting market economy } \\
\quad \text { (破坏市场经济秩序) }\end{array}$ & $\begin{array}{l}\text { financial fraud ( 金融诈骗); producing or selling fake } \\
\text { commodities (生产、销售伪劣商品) }\end{array}$ & 41,127 \\
\hline $\begin{array}{l}\text { \#6: Embezzlement and bribery } \\
\text { (贪污贿赂) }\end{array}$ & $\begin{array}{l}\text { bribery (受贿、行贿); embezzlement (贪污); misappropriation } \\
\text { of public funds (挪用公款) }\end{array}$ & 15,737 \\
\hline $\begin{array}{l}\text { \#7: Dereliction of duty } \\
\text { (渎职) }\end{array}$ & $\begin{array}{l}\text { abusing power (滥用职权); neglect of duty (玩忽职守); } \\
\text { malpractice for personal gain (徇私舞弊) }\end{array}$ & 2,510 \\
\hline Total & & 981,289 \\
\hline
\end{tabular}

Note. Chinese translations originally appearing in the Criminal Law of China are shown in parentheses. 
Table 2. Name-Level (Character-Level) Analysis Predicting the Crime Risk Index (CRI), Generally for All Crime Categories and Specifically for Each of the Seven Crime Categories.

OLS regression (name-level outcome: Crime Risk Index [CRI])

\begin{tabular}{|c|c|c|c|c|c|c|c|c|}
\hline Predictor & Overall & Crime \#1 & Crime \#2 & Crime \#3 & Crime \#4 & Crime $\# 5$ & Crime \#6 & Crime \#7 \\
\hline Full dataset & (1) & (2) & (3) & (4) & (5) & (6) & (7) & (8) \\
\hline \multirow[t]{2}{*}{ Name popularity } & $-0.421^{* * *}$ & $-0.483^{* * *}$ & $-0.502^{* * *}$ & $-0.433^{* * *}$ & $-0.571^{* * *}$ & $-0.641^{* * *}$ & $-0.733^{* * *}$ & $-0.853^{* * *}$ \\
\hline & $(0.020)$ & $(0.020)$ & $(0.021)$ & $(0.021)$ & $(0.019)$ & $(0.022)$ & $(0.022)$ & $(0.025)$ \\
\hline \multirow[t]{2}{*}{ Name valence } & $-0.256^{* * *}$ & $-0.204^{* * *}$ & $-0.221^{* * *}$ & $-0.247^{* * *}$ & $-0.118^{* * *}$ & $-0.077^{*}$ & -0.053 & 0.050 \\
\hline & $(0.033)$ & $(0.034)$ & $(0.035)$ & $(0.035)$ & $(0.032)$ & $(0.035)$ & $(0.035)$ & $(0.038)$ \\
\hline \multirow[t]{2}{*}{ Name warmth } & $-0.162^{* * *}$ & $-0.143^{* * *}$ & $-0.125^{* * *}$ & $-0.161^{* * *}$ & $-0.147^{* * *}$ & $-0.117^{* * *}$ & $-0.086^{* *}$ & $-0.078^{*}$ \\
\hline & $(0.026)$ & $(0.027)$ & $(0.027)$ & $(0.028)$ & $(0.026)$ & $(0.028)$ & $(0.028)$ & $(0.031)$ \\
\hline \multirow[t]{2}{*}{ Name competence } & $0.166^{* * *}$ & $0.126^{* * *}$ & $0.141^{* * *}$ & $0.205^{* * *}$ & $0.091^{* * *}$ & $0.087^{* * *}$ & $0.163^{* * *}$ & $0.089^{* * *}$ \\
\hline & $(0.023)$ & $(0.023)$ & $(0.024)$ & $(0.024)$ & $(0.022)$ & $(0.025)$ & $(0.025)$ & $(0.027)$ \\
\hline$N$ (name characters) & 2,470 & 2,257 & 2,017 & 2,264 & 2,217 & 1,682 & 1,307 & 711 \\
\hline$R^{2}$ & 0.424 & 0.451 & 0.467 & 0.409 & 0.503 & 0.531 & 0.594 & 0.717 \\
\hline Female subset & (9) & (10) & (11) & (12) & (13) & (14) & (15) & (16) \\
\hline \multirow[t]{2}{*}{ Name popularity } & $-0.646^{* * *}$ & $-0.746^{* * *}$ & $-0.646^{* * *}$ & $-0.767^{* * *}$ & $-0.697^{* * *}$ & $-0.780^{* * *}$ & $-0.825^{* * *}$ & $-0.883^{* * *}$ \\
\hline & $(0.022)$ & $(0.024)$ & $(0.028)$ & $(0.026)$ & $(0.024)$ & $(0.026)$ & $(0.031)$ & $(0.041)$ \\
\hline \multirow[t]{2}{*}{ Name valence } & 0.044 & $0.176^{* * *}$ & -0.080 & $0.119^{* *}$ & $0.088^{*}$ & $0.107^{*}$ & 0.047 & -0.001 \\
\hline & $(0.036)$ & $(0.040)$ & $(0.046)$ & $(0.042)$ & $(0.039)$ & $(0.042)$ & $(0.047)$ & $(0.063)$ \\
\hline \multirow[t]{2}{*}{ Name warmth } & $-0.140^{* * *}$ & $-0.191^{* * *}$ & $-0.153^{* * *}$ & $-0.115^{* * *}$ & $-0.161^{* * *}$ & $-0.111^{* * *}$ & $-0.096^{*}$ & -0.094 \\
\hline & $(0.028)$ & $(0.032)$ & $(0.036)$ & $(0.034)$ & $(0.031)$ & $(0.033)$ & $(0.040)$ & $(0.059)$ \\
\hline \multirow[t]{2}{*}{ Name competence } & 0.009 & 0.027 & $0.078^{*}$ & 0.031 & 0.028 & 0.008 & $0.202^{* * *}$ & $0.146^{* * *}$ \\
\hline & $(0.026)$ & $(0.028)$ & $(0.031)$ & $(0.030)$ & $(0.027)$ & $(0.029)$ & $(0.034)$ & $(0.043)$ \\
\hline$N$ (name characters) & 1,734 & 1,220 & 905 & 959 & 1,387 & 972 & 463 & 137 \\
\hline$R^{2}$ & 0.481 & 0.543 & 0.580 & 0.559 & 0.520 & 0.591 & 0.673 & 0.816 \\
\hline Male subset & (17) & $(18)$ & (19) & (20) & (21) & (22) & (23) & (24) \\
\hline \multirow[t]{2}{*}{ Name popularity } & $-0.490^{* * *}$ & $-0.501^{* * *}$ & $-0.572^{* * *}$ & $-0.498^{* * *}$ & $-0.619^{* * *}$ & $-0.666^{* * *}$ & $-0.760^{* * *}$ & $-0.867^{* * *}$ \\
\hline & $(0.019)$ & $(0.020)$ & $(0.021)$ & $(0.020)$ & $(0.019)$ & $(0.023)$ & $(0.024)$ & $(0.029)$ \\
\hline \multirow[t]{2}{*}{ Name valence } & $-0.125^{* * *}$ & $-0.100^{* *}$ & $-0.073^{*}$ & $-0.115^{* * *}$ & 0.007 & 0.037 & 0.061 & $0.187^{* * *}$ \\
\hline & $(0.032)$ & $(0.033)$ & $(0.034)$ & $(0.034)$ & $(0.032)$ & $(0.038)$ & $(0.038)$ & $(0.044)$ \\
\hline \multirow[t]{2}{*}{ Name warmth } & -0.018 & -0.002 & 0.018 & -0.017 & -0.021 & -0.026 & -0.011 & -0.008 \\
\hline & $(0.025)$ & $(0.026)$ & $(0.027)$ & $(0.027)$ & $(0.026)$ & $(0.029)$ & $(0.030)$ & $(0.035)$ \\
\hline \multirow[t]{2}{*}{ Name competence } & $-0.166^{* * *}$ & $-0.200^{* * *}$ & $-0.194^{* * *}$ & $-0.150^{* * *}$ & $-0.186^{* * *}$ & $-0.137^{* * *}$ & $-0.070^{*}$ & $-0.122^{* * *}$ \\
\hline & $(0.022)$ & $(0.023)$ & $(0.024)$ & $(0.024)$ & $(0.022)$ & $(0.026)$ & $(0.027)$ & $(0.031)$ \\
\hline$N$ (name characters) & 2,442 & 2,218 & 1,971 & 2,236 & 2,160 & 1,541 & 1,241 & 669 \\
\hline$R^{2}$ & 0.471 & 0.475 & 0.510 & 0.454 & 0.517 & 0.512 & 0.566 & 0.648 \\
\hline
\end{tabular}

Note. Standardized coefficients $(\beta)$ are displayed, with standard errors $(S E)$ in parentheses. All models satisfied multivariate normal distribution. The VIF (variance inflation factor) of all predictors in all models were lower than 5 , indicating no problem of multicollinearity.

$* p<.05 . * * p<.01 .{ }^{* * *} p<.001$. 
Table 3. Individual-Level Analysis Predicting Criminal Behavior (Across All Crime Categories).

\begin{tabular}{|c|c|c|c|c|c|c|}
\hline \multirow[b]{2}{*}{ Predictor } & \multicolumn{6}{|c|}{ Logistic regression } \\
\hline & (1) & (2) & (3) & (4) & (5) & (6) \\
\hline \multicolumn{7}{|l|}{ Name variable } \\
\hline \multirow[t]{2}{*}{ Name popularity } & $-0.217^{* * *}$ & & & & $-0.122^{* * *}$ & $-0.064^{* * *}$ \\
\hline & $(0.002)$ & & & & $(0.003)$ & $(0.003)$ \\
\hline \multirow[t]{2}{*}{ Surname popularity } & & $-0.061^{* * *}$ & & & $-0.062^{* * *}$ & $-0.065^{* * *}$ \\
\hline & & $(0.002)$ & & & $(0.002)$ & $(0.002)$ \\
\hline \multirow[t]{2}{*}{ Name valence } & & & $-0.147^{* * *}$ & & $-0.508^{* * *}$ & $0.103^{* * *}$ \\
\hline & & & $(0.004)$ & & $(0.007)$ & $(0.009)$ \\
\hline \multirow[t]{2}{*}{ Name warmth } & & & & $-0.630^{* * *}$ & $-0.204^{* * *}$ & $-0.120^{* * *}$ \\
\hline & & & & $(0.005)$ & $(0.007)$ & $(0.008)$ \\
\hline \multirow[t]{2}{*}{ Name competence } & & & & $0.991^{* * *}$ & $1.238^{* * *}$ & $0.037^{* * *}$ \\
\hline & & & & $(0.006)$ & $(0.006)$ & $(0.008)$ \\
\hline \multicolumn{7}{|l|}{ Control variable } \\
\hline \multirow[t]{2}{*}{ Gender } & & & & & & $2.565^{* * *}$ \\
\hline & & & & & & $(0.005)$ \\
\hline \multirow[t]{2}{*}{ Age } & & & & & & $-0.004^{* * *}$ \\
\hline & & & & & & $(0.000)$ \\
\hline \multirow[t]{2}{*}{ Education } & & & & & & $-0.250^{* * *}$ \\
\hline & & & & & & $(0.002)$ \\
\hline$n$ (criminal cases) & 981,289 & 981,289 & 981,289 & 981,289 & 981,289 & 810,610 \\
\hline$n$ (non-criminal controls) & $1,000,000$ & $1,000,000$ & $1,000,000$ & $1,000,000$ & $1,000,000$ & $1,000,000$ \\
\hline Nagelkerke's $R^{2}$ & 0.005 & 0.001 & 0.001 & 0.024 & 0.032 & 0.290 \\
\hline
\end{tabular}

Note. Unstandardized coefficients are displayed, with standard errors $(S E)$ in parentheses. Gender: $0=$ female, 1 = male. The VIF (variance inflation factor) of all predictors in all models were lower than 5 , indicating no problem of multicollinearity.

$* p<.05 . * * p<.01 . * * * p<.001$. 
Table 4. Individual-Level Analysis Predicting Seven Categories of Criminal Behavior (Without

Demographic Controls).

\begin{tabular}{|c|c|c|c|c|c|c|c|}
\hline \multirow[b]{2}{*}{ Predictor } & \multicolumn{7}{|c|}{ Multinomial logistic regression } \\
\hline & Crime \#1 & Crime \#2 & Crime \#3 & Crime \#4 & Crime \#5 & Crime \#6 & Crime \#7 \\
\hline \multicolumn{8}{|l|}{ Model 1} \\
\hline \multirow[t]{2}{*}{ Name popularity } & $-0.245^{* * *}$ & $-0.208^{* * *}$ & $-0.192^{* * *}$ & $-0.239^{* * *}$ & $-0.144^{* * *}$ & $-0.192^{* * *}$ & $-0.159^{* * *}$ \\
\hline & $(0.003)$ & $(0.005)$ & $(0.003)$ & $(0.004)$ & $(0.008)$ & $(0.013)$ & $(0.033)$ \\
\hline \multicolumn{8}{|l|}{ Model 2} \\
\hline \multirow[t]{2}{*}{ Surname popularity } & $-0.077^{* * *}$ & $-0.038^{* * *}$ & $-0.043^{* * *}$ & $-0.084^{* * *}$ & $-0.045^{* * *}$ & $-0.059^{* * *}$ & -0.034 \\
\hline & $(0.003)$ & $(0.004)$ & $(0.003)$ & $(0.003)$ & $(0.007)$ & $(0.011)$ & $(0.027)$ \\
\hline \multicolumn{8}{|l|}{ Model 3} \\
\hline \multirow[t]{2}{*}{ Name valence } & $-0.168^{* * *}$ & $-0.220^{* * *}$ & $-0.139^{* * *}$ & $-0.110^{* * *}$ & $-0.079^{* * *}$ & -0.007 & 0.099 \\
\hline & $(0.006)$ & $(0.008)$ & $(0.006)$ & $(0.007)$ & $(0.014)$ & $(0.023)$ & $(0.057)$ \\
\hline \multicolumn{8}{|l|}{ Model 4} \\
\hline \multirow[t]{2}{*}{ Name warmth } & $-0.659^{* * *}$ & $-0.651^{* * *}$ & $-0.674^{* * *}$ & $-0.568^{* * *}$ & $-0.423^{* * *}$ & $-0.439^{* * *}$ & $-0.413^{* * *}$ \\
\hline & $(0.008)$ & $(0.011)$ & $(0.007)$ & $(0.009)$ & $(0.018)$ & $(0.029)$ & $(0.073)$ \\
\hline \multirow[t]{2}{*}{ Name competence } & $0.968^{* * *}$ & $0.950^{* * *}$ & $1.111^{* * *}$ & $0.914^{* * *}$ & $0.717^{* * *}$ & $1.054^{* * *}$ & $1.036^{* * *}$ \\
\hline & $(0.008)$ & $(0.012)$ & $(0.008)$ & $(0.009)$ & $(0.019)$ & $(0.031)$ & $(0.076)$ \\
\hline \multicolumn{8}{|l|}{ Model 5} \\
\hline \multirow[t]{2}{*}{ Name popularity } & $-0.155^{* * *}$ & $-0.077^{* * *}$ & $-0.075^{* * *}$ & $-0.179^{* * *}$ & $-0.079^{* * *}$ & $-0.132^{* * *}$ & -0.075 \\
\hline & $(0.004)$ & $(0.006)$ & $(0.004)$ & $(0.005)$ & $(0.010)$ & $(0.016)$ & $(0.039)$ \\
\hline \multirow[t]{2}{*}{ Surname popularity } & $-0.077^{* * *}$ & $-0.038^{* * *}$ & $-0.045^{* * *}$ & $-0.085^{* * *}$ & $-0.046^{* * *}$ & $-0.061^{* * *}$ & -0.036 \\
\hline & $(0.003)$ & $(0.004)$ & $(0.003)$ & $(0.003)$ & $(0.007)$ & $(0.011)$ & $(0.027)$ \\
\hline \multirow[t]{2}{*}{ Name valence } & $-0.454^{* * *}$ & $-0.671^{* * *}$ & $-0.623^{* * *}$ & $-0.345^{* * *}$ & $-0.362^{* * *}$ & $-0.509^{* * *}$ & $-0.661^{* * *}$ \\
\hline & $(0.011)$ & $(0.015)$ & $(0.010)$ & $(0.012)$ & $(0.025)$ & $(0.041)$ & $(0.101)$ \\
\hline \multirow[t]{2}{*}{ Name warmth } & $-0.245^{* * *}$ & $-0.146^{* * *}$ & $-0.205^{* * *}$ & $-0.212^{* * *}$ & $-0.120^{* * *}$ & -0.007 & 0.090 \\
\hline & $(0.010)$ & $(0.015)$ & $(0.010)$ & $(0.012)$ & $(0.024)$ & $(0.038)$ & $(0.096)$ \\
\hline \multirow[t]{2}{*}{ Name competence } & $1.193^{* * *}$ & $1.274^{* * *}$ & $1.412^{* * *}$ & $1.086^{* * *}$ & $0.889^{* * *}$ & $1.298^{* * *}$ & $1.345^{* * *}$ \\
\hline & $(0.010)$ & $(0.014)$ & $(0.009)$ & $(0.011)$ & $(0.023)$ & $(0.036)$ & $(0.090)$ \\
\hline
\end{tabular}

Note. Pooled $N=1,981,289(n=981,289$ criminal cases and $n=1,000,000$ non-criminal controls [a national representative sample]). Unstandardized coefficients are displayed, with standard errors $(S E)$ in parentheses. Crime \#1: violating property. Crime \#2: infringing personal rights. Crime \#3: endangering public security. Crime \#4: obstructing social management. Crime \#5: disrupting market economy. Crime \#6: embezzlement and bribery. Crime \#7: dereliction of duty.

$* p<.05 . * * p<.01 . * * * p<.001$. 
Table 5. Individual-Level Analysis Predicting Seven Categories of Criminal Behavior (Controlling for Gender, Age, and Education).

\begin{tabular}{|c|c|c|c|c|c|c|c|}
\hline \multirow[b]{2}{*}{ Predictor } & \multicolumn{7}{|c|}{ Multinomial logistic regression } \\
\hline & Crime \#1 & Crime \#2 & Crime \#3 & Crime \#4 & Crime \#5 & Crime \#6 & Crime \#7 \\
\hline \multicolumn{8}{|l|}{ Model 1} \\
\hline \multirow[t]{2}{*}{ Name popularity } & $-0.061^{* * *}$ & $-0.044^{* * *}$ & -0.008 & $-0.108^{* * *}$ & $-0.034^{* * *}$ & $0.074^{* * *}$ & $0.113^{* *}$ \\
\hline & $(0.004)$ & $(0.006)$ & $(0.004)$ & $(0.005)$ & $(0.009)$ & $(0.015)$ & $(0.036)$ \\
\hline \multicolumn{8}{|l|}{ Model 2} \\
\hline \multirow[t]{2}{*}{ Surname popularity } & $-0.084^{* * *}$ & $-0.041^{* * *}$ & $-0.048^{* * *}$ & $-0.085^{* * *}$ & $-0.048^{* * *}$ & $-0.062^{* * *}$ & -0.028 \\
\hline & $(0.003)$ & $(0.005)$ & $(0.003)$ & $(0.004)$ & $(0.007)$ & $(0.012)$ & $(0.029)$ \\
\hline \multicolumn{8}{|l|}{ Model 3} \\
\hline \multirow[t]{2}{*}{ Name valence } & $-0.043^{* * *}$ & $-0.051^{* * *}$ & 0.004 & $0.035^{* * *}$ & 0.027 & $0.071^{* *}$ & 0.003 \\
\hline & $(0.007)$ & $(0.009)$ & $(0.006)$ & $(0.008)$ & $(0.015)$ & $(0.026)$ & $(0.061)$ \\
\hline \multicolumn{8}{|l|}{ Model 4} \\
\hline \multirow[t]{2}{*}{ Name warmth } & $-0.075^{* * *}$ & $-0.111^{* * *}$ & $-0.092^{* * *}$ & $-0.105^{* * *}$ & $-0.091^{* * *}$ & -0.015 & 0.025 \\
\hline & $(0.009)$ & $(0.012)$ & $(0.008)$ & $(0.010)$ & $(0.020)$ & $(0.034)$ & $(0.079)$ \\
\hline \multirow[t]{2}{*}{ Name competence } & -0.014 & $0.062^{* * *}$ & $0.091^{* * *}$ & $0.173^{* * *}$ & $0.126^{* * *}$ & $0.153^{* * *}$ & -0.034 \\
\hline & $(0.010)$ & $(0.014)$ & $(0.009)$ & $(0.011)$ & $(0.022)$ & $(0.037)$ & $(0.088)$ \\
\hline \multicolumn{8}{|l|}{ Model 5} \\
\hline \multirow[t]{2}{*}{ Name popularity } & $-0.067^{* * *}$ & $-0.031^{* * *}$ & -0.008 & $-0.156^{* * *}$ & $-0.049^{* * *}$ & $0.085^{* * *}$ & $0.139^{* * *}$ \\
\hline & $(0.005)$ & $(0.007)$ & $(0.005)$ & $(0.005)$ & $(0.011)$ & $(0.017)$ & $(0.040)$ \\
\hline \multirow[t]{2}{*}{ Surname popularity } & $-0.084^{* * *}$ & $-0.041^{* * *}$ & $-0.049^{* * *}$ & $-0.085^{* * *}$ & $-0.049^{* * *}$ & $-0.066^{* * *}$ & -0.034 \\
\hline & $(0.003)$ & $(0.005)$ & $(0.003)$ & $(0.004)$ & $(0.007)$ & $(0.012)$ & $(0.029)$ \\
\hline \multirow[t]{2}{*}{ Name valence } & $0.105^{* * *}$ & -0.005 & $0.057^{* * *}$ & $0.218^{* * *}$ & $0.113^{* * *}$ & -0.062 & -0.161 \\
\hline & $(0.013)$ & $(0.018)$ & $(0.012)$ & $(0.014)$ & $(0.028)$ & $(0.047)$ & $(0.112)$ \\
\hline \multirow[t]{2}{*}{ Name warmth } & $-0.105^{* * *}$ & $-0.089^{* * *}$ & $-0.126^{* * *}$ & $-0.155^{* * *}$ & $-0.136^{* * *}$ & -0.033 & 0.058 \\
\hline & $(0.012)$ & $(0.016)$ & $(0.011)$ & $(0.013)$ & $(0.026)$ & $(0.045)$ & $(0.106)$ \\
\hline \multirow[t]{2}{*}{ Name competence } & $-0.051^{* * *}$ & $0.073^{* * *}$ & $0.064^{* * *}$ & $0.092^{* * *}$ & $0.077^{* *}$ & $0.193^{* * *}$ & 0.051 \\
\hline & $(0.012)$ & $(0.016)$ & $(0.011)$ & $(0.013)$ & $(0.026)$ & $(0.045)$ & $(0.105)$ \\
\hline \multirow[t]{2}{*}{ Gender } & $2.673^{* * *}$ & $2.893^{* * *}$ & $3.626^{* * *}$ & $1.879^{* * *}$ & $1.317^{* * *}$ & $1.951^{* * *}$ & $2.361^{* * *}$ \\
\hline & $(0.009)$ & $(0.015)$ & $(0.013)$ & $(0.008)$ & $(0.014)$ & $(0.031)$ & $(0.087)$ \\
\hline \multirow[t]{2}{*}{ Age } & $-0.027^{* * *}$ & $-0.005^{* * *}$ & $0.005^{* * *}$ & $-0.007^{* * *}$ & $0.024^{* * *}$ & $0.101^{* * *}$ & $0.091^{* * *}$ \\
\hline & $(0.000)$ & $(0.000)$ & $(0.000)$ & $(0.000)$ & $(0.000)$ & $(0.001)$ & $(0.002)$ \\
\hline \multirow[t]{2}{*}{ Education } & $-0.603^{* * *}$ & $-0.525^{* * *}$ & $-0.097^{* * *}$ & $-0.533^{* * *}$ & $0.204^{* * *}$ & $1.274^{* * *}$ & $1.332^{* * *}$ \\
\hline & $(0.004)$ & $(0.006)$ & $(0.003)$ & $(0.005)$ & $(0.006)$ & (0.008) & $(0.018)$ \\
\hline
\end{tabular}

Note. All models controlled for gender, age, and education (170,679 missing values in education in the crime data). Pooled $N=1,810,610(n=810,610$ criminal cases and $n=1,000,000$ non-criminal controls [a national representative sample]). Unstandardized coefficients are displayed, with standard errors $(S E)$ in parentheses. Crime \#1: violating property. Crime \#2: infringing personal rights. Crime \#3: endangering public security. Crime \#4: obstructing social management. Crime \#5: disrupting market economy. Crime \#6: embezzlement and bribery. Crime \#7: dereliction of duty. Gender: $0=$ female, $1=$ male.

$* p<.05 . * * p<.01 .{ }^{* * *} p<.001$. 
Table 6. Individual-Level Analysis Predicting Criminal Motive (Intentional vs. Unintentional Crime).

Logistic regression

(individual-level outcome: 0 = unintentional crime, $1=$ intentional crime)

\begin{tabular}{|c|c|c|c|c|c|c|}
\hline \multirow{2}{*}{ Predictor } & & & & & & \\
\hline & (1) & (2) & (3) & (4) & (5) & (6) \\
\hline \multicolumn{7}{|l|}{ Name variable } \\
\hline \multirow[t]{2}{*}{ Name popularity } & $-0.071^{* *}$ & & & & $-0.172^{* * *}$ & -0.003 \\
\hline & $(0.024)$ & & & & $(0.029)$ & $(0.033)$ \\
\hline \multirow[t]{2}{*}{ Surname popularity } & & 0.011 & & & 0.008 & 0.009 \\
\hline & & $(0.018)$ & & & $(0.018)$ & $(0.021)$ \\
\hline \multirow[t]{2}{*}{ Name valence } & & & $0.195^{* * *}$ & & $0.481^{* * *}$ & 0.163 \\
\hline & & & $(0.037)$ & & $(0.074)$ & $(0.085)$ \\
\hline \multirow[t]{2}{*}{ Name warmth } & & & & $-0.265^{* * *}$ & $-0.493^{* * *}$ & $-0.217^{* *}$ \\
\hline & & & & $(0.050)$ & $(0.070)$ & $(0.079)$ \\
\hline \multirow[t]{2}{*}{ Name competence } & & & & $0.553^{* * *}$ & $0.327^{* * *}$ & -0.004 \\
\hline & & & & $(0.055)$ & $(0.067)$ & $(0.079)$ \\
\hline \multicolumn{7}{|l|}{ Control variable } \\
\hline \multirow[t]{2}{*}{ Gender } & & & & & & $0.402^{* * *}$ \\
\hline & & & & & & $(0.059)$ \\
\hline \multirow[t]{2}{*}{ Age } & & & & & & $-0.042^{* * *}$ \\
\hline & & & & & & $(0.001)$ \\
\hline \multirow[t]{2}{*}{ Education } & & & & & & $0.072^{*}$ \\
\hline & & & & & & $(0.032)$ \\
\hline$n$ (intentional cases) & 108,141 & 108,141 & 108,141 & 108,141 & 108,141 & 89,162 \\
\hline$n$ (unintentional cases) & 5,309 & 5,309 & 5,309 & 5,309 & 5,309 & 4,171 \\
\hline Nagelkerke's $R^{2}$ & 0.000 & 0.000 & 0.001 & 0.003 & 0.004 & 0.040 \\
\hline
\end{tabular}

Note. Unstandardized coefficients are displayed, with standard errors $(S E)$ in parentheses. Gender: $0=$ female, 1 = male. The VIF (variance inflation factor) of all predictors in all models were lower than 5, indicating no problem of multicollinearity. For subcategories of intentional and unintentional crime, see Table S2.

$* p<.05 .{ }^{* *} p<.01 .{ }^{* * *} p<.001$. 


\section{Supplementary Tables}

Table S1. Sample Sizes in Stratified Sampling for a National Representative Sample of Non-Criminal Controls.

\begin{tabular}{|c|c|c|c|c|c|c|c|c|c|c|c|}
\hline \multirow[b]{3}{*}{ Age group } & \multicolumn{10}{|c|}{ Education level } & \multirow[b]{3}{*}{ Total } \\
\hline & \multicolumn{2}{|c|}{1 (junior high or below) } & \multicolumn{2}{|c|}{2 (senior high) } & \multicolumn{2}{|c|}{3 (junior college) } & \multicolumn{2}{|c|}{4 (bachelor) } & \multicolumn{2}{|c|}{5 (master or above) } & \\
\hline & Female & Male & Female & Male & Female & Male & Female & Male & Female & Male & \\
\hline $16 \sim 20$ & 25,758 & 28,035 & 20,044 & 21,956 & 4,834 & 4,192 & 3,551 & 3,330 & 10 & 9 & 111,719 \\
\hline $21 \sim 25$ & 34,904 & 33,269 & 10,943 & 12,820 & 8,084 & 7,852 & 6,051 & 6,337 & 551 & 493 & 121,304 \\
\hline $26 \sim 30$ & 31,983 & 31,165 & 8,470 & 9,883 & 5,397 & 5,451 & 3,932 & 4,210 & 581 & 603 & 101,675 \\
\hline $31 \sim 35$ & 35,077 & 34,529 & 7,760 & 9,381 & 3,977 & 4,398 & 2,358 & 2,866 & 301 & 405 & 101,052 \\
\hline $36 \sim 40$ & 48,299 & 47,089 & 7,989 & 10,343 & 3,400 & 4,252 & 1,811 & 2,622 & 182 & 322 & 126,309 \\
\hline $41 \sim 45$ & 50,195 & 48,420 & 6,691 & 8,975 & 2,253 & 3,171 & 1,204 & 2,097 & 98 & 237 & 123,341 \\
\hline $46 \sim 50$ & 37,454 & 34,617 & 7,934 & 10,648 & 1,651 & 2,627 & 691 & 1,470 & 54 & 180 & 97,326 \\
\hline $51 \sim 55$ & 34,023 & 32,057 & 5,467 & 8,197 & 973 & 1,810 & 322 & 698 & 20 & 71 & 83,638 \\
\hline $56 \sim 60$ & 35,674 & 33,656 & 2,327 & 4,137 & 688 & 1,372 & 234 & 483 & 9 & 31 & 78,611 \\
\hline $61 \sim 65$ & 25,145 & 24,251 & 1,379 & 2,401 & 392 & 891 & 163 & 382 & 5 & 16 & 55,025 \\
\hline Total & 358,512 & 347,088 & 79,004 & 98,741 & 31,649 & 36,016 & 20,317 & 24,495 & 1,811 & 2,367 & $1,000,000$ \\
\hline
\end{tabular}

Note. National population across gender, age, and education level was obtained from the 2010 China census (Table A0401 “全国分年龄、性别、受教育程度的 6 岁 及以上人口"; http://www.stats.gov.cn/tjsj/pcsj/rkpc/6rp/excel/A0401a.xls). According to the national population, we calculated stratum sample sizes required for a total of 1,000,000 cases (as shown in the above table). Then, from the job-hunter data that we collected from Ganji.com, we performed stratified random sampling with replacement by using the R package sampling to get a national representative sample (random seed was set to "1" for reproduction). 
Table S2. Intentional and Unintentional Crime.

\begin{tabular}{|c|c|c|}
\hline \multirow[b]{2}{*}{ Crime category } & \multicolumn{2}{|c|}{ Crime subcategory } \\
\hline & Intentional crime (with a motive) & Unintentional crime (without a motive) \\
\hline $\begin{array}{l}\# 2 \text { : Infringing personal } \\
\text { rights }\end{array}$ & $\begin{array}{l}\text { - 故意杀人 (intentional homicide) } \\
\text { - 故意伤害 (intentional injury) }\end{array}$ & $\begin{array}{l}\text { - 过失致人死亡 (negligent homicide) } \\
\text { - 过失致人重伤 (negligent injury) }\end{array}$ \\
\hline $\begin{array}{l}\# 3 \text { : Endangering public } \\
\text { security }\end{array}$ & $\begin{array}{l}\text { - 放火 (arson) } \\
\text { - 决水 (flooding) } \\
\text { - 爆炸 (explosion) } \\
\text { - 投毒 (poisoning) } \\
\text { - 以危险方法危害公共安全 } \\
\text { (endangering public security) } \\
\text { - 破坏交通工具 } \\
\text { (destroying vehicles) } \\
\text { - 破坏交通设施 } \\
\text { (destructing traffic facilities) } \\
\text { - 破坏电力设备 } \\
\text { (sabotaging electrical power equipment) } \\
\text { - 破坏易燃易爆设备 } \\
\text { (destroying inflammable and explosive equipment) } \\
\text { - 破坏广播电视设施、公用电信设施 } \\
\text { (destructing radio and television facilities, public } \\
\text { telecommunications facilities) }\end{array}$ & $\begin{array}{l}\text { - 失火 (accidental fire) } \\
\text { - 过失决水 (accidental flooding) } \\
\text { - 过失爆炸 (accidental explosion) } \\
\text { - 过失投毒 (accidental poisoning) } \\
\text { - 过失以危险方法危害公共安全 } \\
\text { (accidentally endangering public security) } \\
\text { - 过失损坏交通工具 } \\
\text { (accidentally damaging vehicles) } \\
\text { - 过失损坏交通设施 } \\
\text { (accidentally damaging traffic facilities) } \\
\text { - 过失损坏电力设备 } \\
\text { (accidentally damaging electrical power equipment) } \\
\text { - 过失损坏易燃易爆设备 } \\
\text { (accidentally damaging inflammable and explosive equipment) } \\
\text { - 过失损坏广播电视设施、公用电信设施 } \\
\text { (accidentally damaging radio and television facilities, public } \\
\text { telecommunications facilities) }\end{array}$ \\
\hline
\end{tabular}

Note. Specific reasons of crime are shown in Chinese, with English translations listed in parentheses. 
Table S3. Descriptive Statistics and Correlations.

\begin{tabular}{|c|c|c|c|c|c|c|c|c|c|c|}
\hline Variable & Range & $M \pm S D$ & 1 & 2 & 3 & 4 & 5 & 6 & 7 & 8 \\
\hline \multicolumn{11}{|l|}{ Name variable } \\
\hline 1. Name popularity & $0 \sim 4.82$ & $3.62 \pm 0.59$ & - & N/A & $.62^{* * *}$ & $.57^{* * *}$ & $.40^{* * *}$ & $-.06^{* *}$ & N/A & N/A \\
\hline 2. Surname popularity & $0 \sim 4.87$ & $4.02 \pm 0.73$ & $.02^{* * *}$ & - & N/A & $\mathrm{N} / \mathrm{A}$ & N/A & $\mathrm{N} / \mathrm{A}$ & N/A & N/A \\
\hline 3. Name valence & $-2 \sim 2$ & $0.89 \pm 0.36$ & $.48^{* * *}$ & $.03^{* * *}$ & - & $.81^{* * *}$ & $.74^{* * *}$ & $-.05^{*}$ & $\mathrm{~N} / \mathrm{A}$ & $\mathrm{N} / \mathrm{A}$ \\
\hline 4. Name warmth & $-2 \sim 2$ & $0.53 \pm 0.30$ & $.34^{* * *}$ & $.01^{* * *}$ & $.71^{* * * *}$ & - & $.62^{* * *}$ & $-.13^{* * *}$ & N/A & N/A \\
\hline 5. Name competence & $-2 \sim 2$ & $0.31 \pm 0.29$ & $.14^{* * *}$ & $.02^{* * *}$ & $.59^{* * *}$ & $.38^{* * *}$ & - & $.18^{* * *}$ & $\mathrm{~N} / \mathrm{A}$ & $\mathrm{N} / \mathrm{A}$ \\
\hline 6. Name gender & $-1 \sim 1$ & $0.20 \pm 0.54$ & $-.13^{* * *}$ & $-.01^{* * *}$ & $-.01^{* * *}$ & $-.07^{* * *}$ & $.36^{* * *}$ & - & N/A & N/A \\
\hline \multicolumn{11}{|l|}{ Demographic variable } \\
\hline 7. Gender & $0 / 1$ & $0.72 \pm 0.45$ & $-.12^{* * *}$ & $-.01^{* * *}$ & $-.04^{* * *}$ & $-.06^{* * *}$ & $.23^{* * *}$ & $.73^{* * *}$ & - & N/A \\
\hline 8. Age & $16 \sim 80$ & $38.10 \pm 12.27$ & $.10^{* * *}$ & $.004^{* * *}$ & $-.07^{* * *}$ & $-.003^{* * *}$ & $-.08^{* * *}$ & $-.02^{* * *}$ & $-.01^{* * *}$ & - \\
\hline 9. Education & $1 \sim 5$ & $1.41 \pm 0.79$ & $-.06^{* * *}$ & -.001 & $.05^{* * *}$ & $.02^{* * *}$ & $.06^{* * *}$ & $-.01^{* * *}$ & $-.02^{* * *}$ & $-.16^{* * *}$ \\
\hline
\end{tabular}

Note. Values above and below the diagonal are correlations respectively at the character level in the Chinese name database $(N=2,614)$ and at the individual level in the present data (pooled $N=1,981,289 ; n=981,289$ criminal cases and $n=1,000,000$ non-criminal controls [a national representative sample]). "Name" represents given name. "Surname" represents family name. $M$ and $S D$ are at the individual level. N/A = not applicable. Correlations with medium or larger effect sizes $(|r|>.30)$ are shown in boldface.

$* p<.05 .{ }^{* *} p<.01 .{ }^{* * *} p<.001$. 
Table S4. Supplementary Analysis Focusing on People With the Same Surname Kong (“孔”).

\begin{tabular}{|c|c|c|c|c|c|}
\hline \multirow[b]{2}{*}{ Predictor } & \multicolumn{5}{|c|}{$\begin{array}{l}\text { Logistic regression } \\
\text { (individual-level outcome: } 0=\text { non-criminal, } 1=\text { criminal) }\end{array}$} \\
\hline & (1) & (2) & (3) & (4) & VIF \\
\hline \multicolumn{6}{|l|}{ Name variable } \\
\hline Name popularity (1st character) & $\begin{array}{l}-0.027 \\
(0.068)\end{array}$ & & & $\begin{array}{l}-0.050 \\
(0.112)\end{array}$ & 1.87 \\
\hline Name popularity (2nd character) & $\begin{array}{l}-0.125 \\
(0.066)\end{array}$ & & & $\begin{array}{l}-0.023 \\
(0.103)\end{array}$ & 1.62 \\
\hline Name valence (1 st character) & & $\begin{array}{r}0.064 \\
(0.089)\end{array}$ & & $\begin{array}{r}0.138 \\
(0.224)\end{array}$ & 4.39 \\
\hline Name valence (2nd character) & & $\begin{array}{l}-0.423^{* * *} \\
(0.113)\end{array}$ & & $\begin{array}{r}0.102 \\
(0.244)\end{array}$ & 3.34 \\
\hline Name warmth (1st character) & & & $\begin{array}{r}0.089 \\
(0.096)\end{array}$ & $\begin{array}{r}0.040 \\
(0.200)\end{array}$ & 3.43 \\
\hline Name warmth (2nd character) & & & $\begin{array}{l}-0.486^{* * *} \\
(0.139)\end{array}$ & $\begin{array}{l}-0.452^{*} \\
(0.225)\end{array}$ & 1.94 \\
\hline Name competence (1st character) & & & $\begin{array}{l}-0.028 \\
(0.167)\end{array}$ & $\begin{array}{r}0.120 \\
(0.222)\end{array}$ & 1.39 \\
\hline Name competence (2nd character) & & & $\begin{array}{r}0.144 \\
(0.145)\end{array}$ & $\begin{array}{r}0.019 \\
(0.211)\end{array}$ & 1.62 \\
\hline Control variable & & & & & \\
\hline Gender & & & & $\begin{array}{l}2.098^{* * *} \\
(0.158)\end{array}$ & 1.08 \\
\hline Age & & & & $\begin{array}{l}0.050^{* * *} \\
(0.005)\end{array}$ & 1.04 \\
\hline Education & & & & $\begin{array}{l}-0.752^{* * *} \\
(0.069)\end{array}$ & 1.03 \\
\hline$n$ (criminal cases) & 1,443 & 1,443 & 1,443 & 1,169 & \\
\hline$n$ (non-criminal controls) & 654 & 654 & 654 & 654 & \\
\hline Nagelkerke's $R^{2}$ & 0.003 & 0.010 & 0.009 & 0.347 & \\
\hline
\end{tabular}

Note. Unstandardized coefficients are displayed, with standard errors $(S E)$ in parentheses. To differentiate between "generational" given name (1st character) and "personal" given name (2nd character), we included individuals whose given name consists of two characters into analysis. Gender: $0=$ female, $1=$ male. VIF $=$ variance inflation factor. A VIF above 5 indicates a problem of multicollinearity.

$* p<.05 . * * p<.01 . * * * p<.001$. 